\title{
$\$$ Research Square

\section{FOXA1 is a transcriptional activator of Odf2/Cenexin and regulates primary ciliation}

\section{Sigrid Hoyer-Fender ( $\nabla$ shoyer@gwdg.de )}

Georg-August-University Göttingen https://orcid.org/0000-0002-6349-594X

\section{Christian Carl Czerny}

University of Göttingen: Georg-August-Universitat Gottingen

Anett Borschel

University of Göttingen: Georg-August-Universitat Gottingen

Mingfang Cai

University of Göttingen: Georg-August-Universitat Gottingen

\section{Madeline Otto}

University of Göttingen: Georg-August-Universitat Gottingen

\section{Research Article}

Keywords: primary cilia, ciliogenesis, transcription, FOXA1, ODF2

Posted Date: February 14th, 2022

DOI: https://doi.org/10.21203/rs.3.rs-1314581/v1

License: (c) (i) This work is licensed under a Creative Commons Attribution 4.0 International License. Read Full License 
FOXA1 is a transcriptional activator of Odf2/Cenexin and regulates primary ciliation

Christian Carl Czerny, Anett Borschel, Mingfang Cai, Madeline Otto ${ }^{1}$, and Sigrid Hoyer-Fender ${ }^{*}$

Johann-Friedrich-Blumenbach-Institute of Zoology and Anthropology - Developmental Biology,

GZMB, Ernst-Caspari-Haus, Justus-von-Liebig-Weg 11, Georg-August-Universität Göttingen, Germany

${ }^{1}$ present address: Thermo Fisher Scientific GENEART, Regensburg

*correspondence to: shoyer@gwdg.de; Orcid-ID: 0000-0002-6349-594X 


\begin{abstract}
Primary cilia are sensory organelles essential for embryonic and postnatal development, and tissue homeostasis in adulthood. They are generated in a cell cycle-dependent manner and found on most cells of the body. Although cilia formation is intensively investigated virtually nothing is known about the transcriptional regulation of primary ciliation. We used here Odf2/Cenexin, encoding a protein of the mother centriole and the basal body that is mandatory for primary cilia formation, as the starting point for the identification of transcriptional activators. We identified a consensus binding site for Fox transcription factors (TFs) in its promoter region and focused here on the Fox family. We found transcriptional activation of Odf2 neither by FOXO TFs nor by the core TF for multiciliation, FOXJ1. However, we identified FOXA1 as a transcriptional activator of Odf2 by reporter gene assays and qRTPCR, and showed by qWB that Foxa1 knockdown caused a decrease in ODF2 and CP110 proteins. We verified the binding sequence of FOXA1 in the Odf2 promoter by ChIP. Finally, we demonstrated that knockdown of FOXA1 affected primary cilia formation. We, thus, showed for the first time, that FOXA1 regulates primary ciliation by transcriptional activation of ciliary genes.
\end{abstract}

Key words: primary cilia, ciliogenesis, transcription, FOXA1, ODF2 


\section{Introduction}

Cilia are microtubule-based structures protruding from the cell surface into the environment. They are assembled at the distal part of the basal body, which is the former mother centriole. Basal bodies are attached to the cell membrane via their distal appendages thus exposing the ciliary axoneme outward. The core axonemal structure of all eukaryotic cilia and flagella consists of nine doublet microtubules arranged in a ring. This organization is known as a 9+0 structure and is found in immotile cilia [1]. The presence of two additional singlet microtubules and further accessory structures, as e.g., dynein arms, characterizes motile cilia that are present in multitudes on the surface of specialized epithelial cells, as those in the airway, the brain ventricles, and oviducts. Their coordinated movement enables the transport of fluids or cargos across the cell surface. In contrast, immotile cilia are present only once and are hence named primary or mono-cilia. Furthermore, primary cilia are found on the surface of nearly all cells of the body $[2,3]$. Primary cilia are essential sensory organelles, acting as mechanoand chemo-sensors and transducing signals in response to fluid flow in kidneys, mechanical load in bone, or ligand-activated receptors. Primary cilia are thus crucial for embryonic and postnatal development, and tissue homeostasis in adulthood. Dysfunctional primary cilia are causative for a large number of severe heritable diseases and syndromes, collectively classified as ciliopathies, as kidney and liver diseases, neural tube defects, and defects in leftright asymmetry [4-10].

The generation of primary cilia is coordinated with the cell cycle and, vice versa, primary cilia might also affect the progression of the cell cycle and cell proliferation $[11,12]$. The formation of primary cilia starts in the G1-phase of the cell cycle and they are disassembled before mitosis [13-15]. However, primary cilia are predominantly found in cell-cycle arrested cells that have withdrawn from the cell cycle in the early G1 phase and entered a quiescent state (G0) $[11,12,16,17]$. In differentiated cells, quiescence is the terminal stage. However, when reversible, cells can be induced to re-enter the cell cycle in response to growth signals. Reversible quiescence characterises tissue-resident stem cells that function in replenishing tissue loss throughout life but is also found in non-stem cells, e.g. in endothelial cells [18]. Extrinsic and intrinsic factors regulate the cell cycle culminating in the activation of cyclindependent kinases, CDKs, by the binding to their regulatory cyclins that together drive the cell through the cell cycle [19-22]. The differential expression of cyclins throughout the cell cycle 
is mandatory for cell cycle progression [23, 24]. Furthermore, cyclin-dependent kinase inhibitors, CKls, antagonize cell cycle progression [22]. Extrinsic factors, as nutrients and growth factors, activate the mitogen-induced signaling pathway (MAPK pathway) and the serine/threonine-protein kinase B (PI3K/AKT) pathway eventually inducing transcription of cyclin $D$ that binds and activates CDK4/6 thus initiating progression from $\mathrm{G} 1$ to $\mathrm{S}$ phase and cell proliferation [22]. On the other hand, low nutrient levels favour cell cycle arrest by increased AMP/ATP and ADP/ATP ratios which activate the energy-sensing AMP-activated protein kinase, AMPK. In between genes activated by AMPK is FOXO3a (also named FOXO3 or FOXO2)[25]. FOXO proteins are regulators of the cell cycle, metabolism, and apoptosis, and are inhibited by AKT-mediated phosphorylation [26-29]. Notably, FOXO3a inhibits mitochondrial gene expression, activates transcription of antioxidant enzymes, and regulates cell cycle progression [30-33]. Activation of FOXO3a, thus, correlates with cell cycle arrest and the formation of primary cilia.

The FOXO proteins belong to the large family of forkhead transcription factors (TFs) characterized by a winged-helix DNA-binding domain of $\sim 110$ amino acids (aa), termed the 'forkhead box' serving as the eponym for the whole Fox family [34-36]. The founding member fork head $(f k h)$ was first identified in Drosophila as a region-specific homeotic gene required for the formation of terminal embryonic structures [37, 38]. Soon thereafter, related genes were identified in diverse organisms ranging from yeast to humans. FOX TFs are evolutionary conserved and are required for a wide variety of biological functions in development and differentiation, and tissue homeostasis [39]. They have been categorized by sequence similarities into subclasses A to S [40]. The hepatocyte nuclear factor 3 forkhead homolog 4, $\mathrm{HFH} 4$, now renamed into FOXJ1, is essential for the formation of motile cilia. Homozygous Foxj1-deficient mice displayed randomized left-right asymmetry and a complete loss of motile multi-cilia in epithelial cells whereas sensory mono-cilia were present [41, 42]. FOXJ1 is an essential component of the transcription factor network controlling the formation of motile cilia by regulating the expression of essential ciliary genes [43-46]. However, while a substantial insight into the transcriptional regulation of motile cilia has already been accumulated our knowledge about the transcriptional regulation of sensory mono-cilia is inconsiderable. Although cilia are built by hundreds of proteins, ODF2/Cenexin, which is a subdistal appendage protein that marks the mother centriole and its derivative, the basal body, is mandatory for cilia formation [1, 47-50]. Odf2-deficient cells miss the primary cilium and 
Odf $2 \%$ mice die during preimplantation $[51,52]$. Furthermore, initiation of ciliogenesis depends on a crucial amount of ODF2 present at the mother centriole [53]. The tight regulation of $\mathrm{Odf2}$, therefore, seems to be mandatory for the generation of primary cilia. Transcription of Odf2 is under control of the stress-activated JNK-pathway, and the transcription factors $\mathrm{C} / \mathrm{EBP} \alpha$, and PAX6 are positive regulators of Odf2 transcription whereas the core TFs for the formation of motile cilia, RFX3 and FOXJ1, are not involved $[54,55]$. Since FOX TFs are essential for diverse biological functions, including cell cycle regulation and motile cilia formation, we asked whether FOX TFs might also be involved in the regulation of primary cilia formation. We identified a putative forkhead box binding site in the Odf2 promoter and analysed the effect of FOX TFs on the expression of Odf2 and the generation of primary cilia. Our data demonstrated that FOXA1 is a transcriptional activator of Odf2 in mouse fibroblasts and promotes the formation of primary cilia. 


\section{Materials and Methods}

\section{Cell culture and immune-cytology}

The mouse fibroblast line NIH3T3 was obtained from DSMZ (ACC59) and cultivated in Dulbecco's Modified Eagle's Medium (DMEM; GlutaMax ${ }^{\mathrm{TM}}$ with high glucose concentration (4.5g/l); ThermoFisher Scientific, \#10566), supplemented with $10 \%(\mathrm{v} / \mathrm{v}$ ) fetal calf serum (FCS), $1,000 \mathrm{U} / \mathrm{ml}$ penicillin and $1,000 \mathrm{\mu g} / \mathrm{ml}$ streptomycin at $37^{\circ} \mathrm{C}$ and $5 \% \mathrm{CO}_{2}$. Primary cilia were induced by cultivation in the above medium supplemented with $0.5 \%$ FCS (serum starvation medium) for 24 to $48 \mathrm{hrs}$.

For immune-cytology, cells were reseeded at a density of $2 \times 10^{5}$ cells per well of a 6-well plate on glass coverslips. Cells were fixed in $3.7 \%$ paraformaldehyde (PFA) for 20 min at $4^{\circ} \mathrm{C}$, permeabilized with $0.3 \%$ Triton X-100 in PBS (phosphate-buffered saline) for 10 min at room temperature, followed by blocking non-specific binding sites by incubation in PBS containing $1 \%$ bovine serum albumin (BSA) and $0.5 \%$ Tween-20 for at least 1 hour. Samples were incubated with the primary antibodies anti-acetylated $\alpha$-Tubulin (clone 6-11B-1; Santa Cruz Biotechnology, Inc., \#sc-23950, diluted 1:50), anti-ARL13B (Proteintech, \#17711-1-AP, diluted 1:400), anti-FOXA1 (Proteintech 20411-1-AP, diluted 1:200), anti-ODF2 (ESAP15572, antibodies-online, diluted 1:100; [56], anti- $\alpha$-Tubulin (Oncogene, \#Ab-1, diluted 1:100) at $4^{\circ} \mathrm{C}$ overnight. Secondary antibodies used are goat anti-mouse-IgG-DyLight 488 (\#35503, ThermoScientific), goat anti-mouse-IgG-AlexaFluor555 (\#A21422, Lot 948498, Invitrogen/Mol. Probes), and goat anti-rabbit-MFP590 (\#MFP-A1037, Molecular Probes, Eugene). DNA was counterstained with DAPI. Images were taken by confocal microscopy (LSM 780, Zeiss) and processed using Adobe Photoshop 7.0. Primary cilia were manually counted by visual inspection and scanning through all focal planes. Approximately 500 cells for each replicate were scored for the presence of a primary cilium. The total counts are given in the results as $\mathrm{n}$, comprising all replicates.

\section{Transfection of cells}

Plasmid DNA or siRNA was transfected using EndoFectin ${ }^{\mathrm{TM}}$ Max Transfection Reagent following the manufacturer's instructions (GeneCopoeia \#EF014). The mouse Foxa1 gene (NM_008259) tagged with Myc-DDK in pCMV6-Entry was obtained from Origene (MR225487). The coding 
region of Foxa1 was cloned in-frame to Egfp in pEGFP-N1 (Clontech). Foxa1 knockdown was achieved using three unique 27mer siRNA duplexes (Origene, SR415184A, SR415184B, SR415184C, all used at a concentration of 10nM), and a universal scrambled negative control siRNA duplex (Origene, SR30004; final concentration 25nM). For Odf2 knockdown, Odf2 siRNA (stealth siRNA ODF2MSS207236; Life Technologies; final concentration 40nM) and control siRNA (siGenome Non-targeting siRNA \#1; ThermoFisher Scientific Biosciences) were used. Additionally, the short hairpin constructs sh3 (specifically targeting sequence gaactcctccaggagatac of mouse Odf2/Cenexin; [55]) or K07 (Origene), which functions as control while lacking homology with any known mRNA, were used. For rescue, the expression plasmid encoding human Cenexin (hCenexin) [57]) was co-transfected, and to identify transfected cells, human histone $H 4$ [58] fused to egfp was also co-transfected.

\section{Expression analyses by reverse-transcribed PCR (RT-PCR) and quantitative RT-PCR (qRT-PCR)}

Total RNA was prepared using peqGOLD RNApure ${ }^{\mathrm{TM}}$ (PeqLab, Erlangen, Germany) following the recommendations of the manufacturer, and digested with Ambion ${ }^{\circledR}$ TURBO DNA-free $^{\text {TM }}$ DNase (Ambion \#AM2238). The absence of genomic DNA was validated via PCR using amplification of Gapdh or Hprt, followed by cDNA synthesis (Maxima First Strand cDNA Synthesis Kit; ThermoFisher Scientific, \#K1641). The following primers were used for expression analyses (RT-PCR): Hprt (mHPRT-for2 ggagtcctgttgatgttgcc/mHPRT-rev2 gggacgcagcaactgacatt), Gapdh (mGapdhf CACCACCAACTGCTTAGCC/mGapdhr CGGATACATTGGGGGTAGG), Foxa1 (for first PCR: Foxa1-for4 tattaccgccagaaccagc/ Foxa1-rev4 acgggtctggaatacacac (expected size: 793bp), and for nested PCR: Foxa1-for1 ccttcaacgattgtttcgtc/Foxa1-rev2 gagaaggggtgattaaaggag (525bp)), Foxo1 (for first PCR: Foxo1for1 gccctacttcaaggataaggg/Foxo1-rev1 cattgtggggaggagagtcag (842bp) and for nested PCR: Foxo1-for2 caagagcggaaaatcaccc/Foxo1-rev2 ctggttcaatcctccgtaacttg (631bp)), Foxo3a (for first PCR: Foxo3a-for1 cttcatgcgcgttcagaatg/Foxo3a-rev1 gtgtctggttgccgtagtg (752bp) and for nested PCR: Foxo3a-for2 gtggatcatcaaccccgatg/Foxo3a-rev2 ccagcccatcattcagattc (449bp)), and Foxj (for first PCR: Foxj-for1 cattctcaacgccaaggc/Foxj-rev1 gatgctgtaggaaggatgtg (1027bp) and for nested PCR: Foxj-for2 caacttctgctacttccgcc/Foxj-rev2 caagaaggtctcatcaaagtc (674bp). The quantitative real-time PCR (qRT-PCR) was performed on CFX96TM Real-Time System (BioRad) using BlazeTaq SYBR Green qPCR mix 2.0 (GeneCopoeia, Rockville, MD). Primer efficiency 
was validated for all primer pairs and the specificity of the amplification reaction was verified by melting curve analyses. The following primer pairs were used for qRT-PCR: Foxa1_f3 (gacgccaagacattcaagcg)/Foxa1_r3 (atcgtgccaccttgacgaaa), Odf2_na-f4 (accatgaaggaccgctcttc)/Odf2 na-r4 (cgcacattcacagtgtcccc), and mHPRT-for2/mHPRT-rev2 and $\mathrm{mGapdhf/mGapdhr}$ as above. Three technical replicates were used for each analysis. The relative expression in each probe was calculated by $\Delta \mathrm{Ct}$ using the average $\mathrm{Ct}$ values of both housekeeping genes as reference. Fold changes were calculated by relation to the average relative expression in the controls.

\section{Reporter gene assay}

NIH3T3 cells were seeded at a density of $1 \times 10^{5}$ cells per well of a 12 well plate. 24 hrs later cells were co-transfected with the reporter vector $(1 \mu \mathrm{g} /$ well) either 2.2-pGL3, or one of the truncated Odf2-promoter vectors $(\# 1,22.1,7.6,7.1,1.5, A 1,0.5)$, in which part of the promoter region was cloned upstream of the firefly luciferase reporter $p G L 3$ [54], and the internal control vector phRL-SV40 (Promega, Madison, USA; 10-100 ng/well), and expression plasmids encoding the following transcription factors (each at 100ng/well): Foxa1 (Origene, MR225487), Foxo1 (addgene 12148), Foxo1 ADA (addgene 12143, constitutively active, containing three point mutations Thr24Ala, Ser253Asp, Ser316Ala), Foxo3a (addgene 1787), Foxj (Steven Brody, St. Louis), Rfx3 (Walter Reith, Genf), C/Ebp $($ addgene 12550), and cJun (pFA2-cJun, encoding the transactivation domain of aa 1-223) and Mekk1 (MAP3K1; pFCMEKK, aa 380-672) both from Stratagene (PathDetect cJun trans-Reporting System; Stratagene, La Jolla, USA). The Odf2 promoter constructs cloned upstream of the firefly luciferase in pGL3 are $2.2(-1805 /+358), 7.1(-1805 /-94), 7.6(-1805 /-1282), 22.1$ (-1805/1368), \#1 (-1675/+1), $1.5(-797 /+1), A 1(-797 /+358)$, and $0.5(-94 /+255)$ [54]. To investigate the effect of FOXA1 knockdown on reporter gene activity, the Foxa1 expression plasmid (Origene, MR225487) (100 ng/well), and either one of the Foxa1 siRNA duplexes (Origene, SR415184A, SR415184B, or SR415184C, all used at a final concentration of 20nM), or a universal scrambled negative control siRNA duplex (Origene, SR30004; final concentration $25 \mathrm{nM}$ ) were co-transfected. Cells were either cultivated in standard medium for $24 \mathrm{hrs}$ posttransfection (cycling cells), or the medium was exchanged for serum starvation medium $24 \mathrm{hrs}$ post-transfection, and cells cultivated for another $48 \mathrm{hrs}$ (serum-starved cells). The Dual-Glo Luciferase Assay System (Promega, USA) was used for measuring firefly and Renilla luciferase 
activity using the Centro LB 960 luminometer (Berthold Technologies, Germany). Fold changes were calculated based on the relative luminescence (firefly luminescence/Renilla luminescence). Each experiment was performed in triplicates and repeated up to six times.

\section{Co-immune-precipitation and Western blotting}

Cells were transfected with the expression plasmids either Foxa1::Gfp or Foxa1::Gfp and Mekk1 (MAP3K1; pFC-MEKK, aa 380-672). 24hrs post-transfection cells were trypsinised and lysed in RIPA-buffer (50 mM Tris pH 7.6, $150 \mathrm{mM} \mathrm{NaCl}, 1 \%$ Nonidet P40, 0.5\% sodium desoxycholate, $0.1 \%$ SDS, protease inhibitor mix ProteoBlock Protease inhibitor Cocktail, Fermentas R1321) by vortexing and sonication (3x $45 \mathrm{sec}$ each). The supernatant was incubated with GFP Trap Magnetic Agarose (chromotek, gtma-20) for $1 \mathrm{~h}$ at $4^{\circ} \mathrm{C}$ on a rotating wheel. Beads were, thereafter, washed 4-times with $500 \mu$ I RIPA-buffer each, and $10 \%$ of each wash solution stored for later analysis. Bead-bound proteins were eluted by boiling in SDSsample buffer containing ß-mercaptoethanol for 5 min.

Proteins were separated on denaturing SDS-gels and transferred to Hybond ECL $[59,60]$. Blot membranes were blocked for $1 \mathrm{hr}$ in 5\% dry milk in TBST (10 mM Tris- $\mathrm{HCl}$ pH 7.6, $150 \mathrm{mM}$ $\mathrm{NaCl}, 0.05 \%$ Tween 20), and incubated with the primary antibodies (rabbit anti-GFP, self-made, and mouse monoclonal anti-cJUN, proteintech 66313-1-lg) overnight at $4^{\circ} \mathrm{C}$. For quantitative Western blots anti-ODF2 (ESAP15572, antibodies-online, diluted 1:1,000), and anti-CP110 (Proteintech \#12780-1-AP, diluted 1:3,000) antibodies were used, and as the internal standard anti-ß-Actin antibody (proteintech \#20536-1-AP). Primary antibodies were detected with the fluorescent-labelled secondary antibodies IRDye800CW goat anti-mouse IgG (LI-COR, \#92532210), and IRDye680RD goat anti-rabbit IgG (LI-COR, \#925-68071), or with IRDye800CW goat anti-rabbit IgG (LI-COR, \#925-32211) and IRDye680RD goat anti-mouse IgG (LI-COR, \#92568070). Images were captured with LI-COR Odyssey CLX and analysed using Image Studio Lite (LI-COR). Quantification was performed by calculating the ratio between the target protein and the internal standard (ß-Actin) in the same lane. The relative quantities were then related to the average relative quantity in the control, giving the fold change of target protein expression. 


\section{Chromatin-immune-precipitation}

NIH3T3 were transfected either with the Foxa1 expression plasmid and the Odf2 reporter vector 2.2-pGL3 or with 2.2-pGL3 exclusively to investigate the binding of the endogenous FOXA1. The chromatin-immune-precipitation (ChIP) protocol was a modification of Denissov et al. [61] . Briefly, cells were crosslinked with 1.1\% formaldehyde in PBS (phosphate-buffered saline) containing $0.07 \mathrm{mM}$ EDTA, $0.035 \mathrm{mM}$ EGTA, and $3.5 \mathrm{mM}$ Hepes for $30 \mathrm{~min}$ at room temperature, quenched by adding glycine to $0.125 \mathrm{M}$ final concentration for $5 \mathrm{~min}$ at room temperature, and afterward washed twice with cold PBS. Cells were lysed in Hepes-buffer B (20 mM Hepes, $10 \mathrm{mM}$ EDTA, $0.5 \mathrm{mM}$ EGTA, 0.25\% Triton X-100) for $10 \mathrm{~min}$ at $4^{\circ} \mathrm{C}$, followed by scraping, and cell collection by centrifugation. Cells were washed once in cold Hepes-buffer C (50 mM Hepes, $1 \mathrm{mM}$ EDTA, $0.5 \mathrm{mM}$ EGTA, $0.15 \mathrm{M} \mathrm{NaCl}$ ), and finally resuspended in incubation-buffer (20 mM Hepes, $0.15 \mathrm{M} \mathrm{NaCl}, 1$ mM EDTA, 0.5 mM EGTA, 1\% Triton X-100 with proteinase inhibitor mix; ProteoBlock Protease inhibitor Cocktail, Fermentas R1321). Probes were sonified using 12 cycles (30 sec on/30 sec off) in the Bioruptor (Diagenode), and clarified by centrifugation.

Protein A Dynabeads (Dynal Biotech, \#10001) were pre-cleared and pre-blocked before using for immune-precipitation. Beads were washed twice in incubation buffer, and once in incubation buffer containing $1 \mathrm{mg} / \mathrm{ml}$ BSA (bovine serum albumin), and incubated in incubation buffer containing $2 \mathrm{mg} / \mathrm{ml} \mathrm{BSA}$ and $100 \mu \mathrm{g} / \mathrm{ml}$ sheared salmon sperm DNA overnight at $4^{\circ} \mathrm{C}$. The next day, beads were washed twice in incubation buffer containing 1 $\mathrm{mg} / \mathrm{ml} \mathrm{BSA}$ and incubated with the sheared chromatin for $1 \mathrm{~h}$ at $4^{\circ} \mathrm{C}$ for pre-clearing. After magnetic beads collection, $10 \%$ of the supernatant was removed and stored as the input sample, and the remaining supernatant was transferred into new tubes and incubated with the antibody, either anti-FOXA1 antibody $(2 \mu \mathrm{g} / 150 \mu \mathrm{l}$ of chromatin; Proteintech \#20411-1$\mathrm{AP}$ ) or rabbit IgG as control (4 $\mathrm{gg} / 150 \mu \mathrm{l}$ of chromatin; Diagenode \#C154110206), together with fresh pre-cleared and pre-blocked beads at $4^{\circ} \mathrm{C}$ overnight on a rotating wheel. The next day, beads were collected and washed twice in wash buffer 1 (20 mM Hepes, 1 mM EDTA, 0.5 mM EGTA, , $0.15 \mathrm{M} \mathrm{NaCl}, 1 \%$ Triton X-100, 0.1\% SDS, 0.1\% sodium deoxycholate (NaDOC)), once in wash buffer 2 (20 mM Hepes, 1 mM EDTA, 0.5 mM EGTA, $0.5 \mathrm{M} \mathrm{NaCl}, 1 \%$ Triton X-100, 0.1\% SDS, 0.1\% NaDOC), once in wash buffer 3 (20 mM Hepes, 1 mM EDTA, 0.5 mM EGTA, $0.25 \mathrm{M} \mathrm{LiCl}, 0.5 \% \mathrm{NaDOC}, 0.5 \% \mathrm{NP}-40$ ), and twice in wash-buffer 4 (20 mM Hepes, $0.5 \mathrm{mM}$ 
EGTA, $1 \mathrm{mM}$ EDTA). Beads and input samples were then incubated with $0.2 \mu \mathrm{g} / \mu \mathrm{l}$ RNase $A$ in

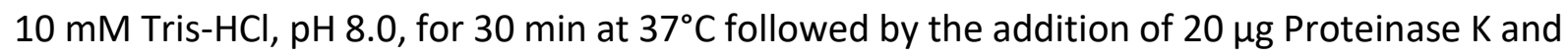
incubated in lysis buffer ( $50 \mathrm{mM}$ Tris- $\mathrm{HCl}, \mathrm{pH} 8.0,10 \mathrm{mM}$ EDTA, $1 \% \mathrm{SDS}$ ) at $65^{\circ} \mathrm{C}$ overnight by constant agitation. DNA was extracted using NucleoSpin Gel and PCR Clean-up (MachereyNagel, \#740609-250).

Binding site occupancy was investigated by qPCR using Foxa1 primers flanking the consensus binding site in the Odf2 promoter (Foxa1-7.6-for GAATTCTGAGATTATAGCTatg/ Foxa1-7.6-rev GCCTTCAGATGTATGTGTGC), or primers flanking a putative DREAM binding-site (DREAM-E1for CTCGTGACCCAGAAGTGG/ DREAM-E1-rev CGGCAGCTCGCCCATTGG). Primers were validated first. The Ct-values obtained by either FOXA1- or control IgG-precipitation were adjusted to their respective input $\mathrm{Ct}(\Delta \mathrm{Ct})$, and the enrichment of the binding site sequence was calculated by adjustment to the control $\lg G(\Delta \Delta C t)$.

\section{Statistical analyses}

Data were processed and analysed using Excel. The box in the boxplots represents the 25-75th percentile. The median is given as a line, the mean by a cross. The whiskers show the minimum and maximum values inside the range given by $Q 1-1.5 x$ interquartile range (IQR) and Q3+1.5xIQR. Data were analysed by Student's T-test, $p<0.05^{*}, p<0.01^{* *}, p<0.001^{* * *}$, $\mathrm{p}<0.0001^{* * * *}$. 


\section{Results}

\section{ODF2 is essential for primary cilia formation}

To validate the relevance of ODF2 for the formation of primary cilia, Odf2 knockdown via transfection with either a short-hairpin plasmid (sh3) or siRNA was performed [62]. The plasmid $\mathrm{KO}$ or the scrambled non-target siRNA served as controls for sh3-or siRNA-mediated knockdown, respectively. For rescue, the human Cenexin plasmid (hCenexin, [57]) was cotransfected with either sh3 or Odf2 siRNA. Additionally, to identify transfected cells, the plasmid encoding histone $\mathrm{H} 4$ fused to Egfp (H4::GFP) was always co-transfected. Cells were fixed 24 hrs post-transfection and primary cilia immunologically decorated for ARL13B (Fig. 1A). Primary cilia were manually counted by visual inspection and scanning through all focal planes taking into consideration only H4::GFP positive cells. We found a clear reduction in primary cilia when Odf2 was knocked down by either the sh3-plasmid or siRNA when compared to the controls (KO7-plasmid or scrambled non-target siRNA, respectively) (Fig. 1B). We have counted $\sim 17 \%$ primary cilia in $K 07$-transfected cells compared to only $\sim 5 \%$ in sh3transfected cells $\left(p=0.000114^{* * *}\right)$, and $\sim 15 \%$ in the siRNA control cells versus $7 \%$ in Odf2 siRNA transfected cells $\left(p=0.022857^{*}\right)$. In contrast, the rescue experiment caused an increase in primary cilia to $\sim 13 \%\left(\right.$ sh $3+$ hCenexin, $\mathrm{p}=0.000989^{+++}$to sh3), and $\sim 21 \%$ (Odf2 siRNA + hCenexin, $\mathrm{p}=0.005358^{++}$to Odf2 siRNA). Our results, thus, confirmed ODF2 as being essential for primary cilia formation.

\section{FOXA1 is a transcriptional activator of the Odf2 promoter}

We previously reported the characterization of the mouse Odf2 promoter and its activation by $C / E B P \alpha$, and the stress-activated JNK-pathway [54]. Furthermore, at position -1775 of the Odf2 promoter, we identified a putative binding site for the forkhead-box transcription factors resembling the consensus binding sequence for FOXO (TT[G/A]TTTAC or GTAAA(T/C)AA; [63]), or FOXA1 (T(G/A)TT(T/G)AC; [64]). To verify whether TFs of the FOX-family are involved in the transcriptional regulation of ciliary genes and the formation of primary cilia, we first investigated the impact of forkhead-box TFs on the activation of the Odf2 promoter controlling expression of the firefly luciferase reporter gene (2.2-pGL3) [54]. The reporter vector 2.2-pGL3 comprised $1.8 \mathrm{~kb}$ upstream of the transcriptional start site of the mouse Odf2 gene together with $358 \mathrm{bp}$ of the transcribed region $(-1805 /+358)$ positioned upstream of the 
firefly luciferase coding sequence. We observed a significant increase in reporter gene activity in cycling cells by Foxa1 co-transfection $\left(p=0.001565^{* *}\right)$, but neither by co-transfection of Foxo1, Foxo3a, Foxj, nor co-transfection of both, Foxj and Rfx3 (Fig. 2A). Additionally, our previous results reporting transcriptional activation by C/EBP $\alpha$, and the JNK-pathway (MEKK1 + cJUN) were verified. The co-transfection of Foxa1 with either C/ebp $\alpha$, Mekk1, cJun, or combinations of these factors revealed that FOXA1 together with C/EBP $\alpha$ has no additive effect on the reporter activity compared to C/EBP $\alpha$. FOXA1 together with MEKK1 significantly increased the reporter gene activity compared to FOXA1 $\left(p=0.026646^{*}\right)$, but without further increase when compared to MEKK1. FOXA1 together with cJUN increased the reporter gene activity to a similar extent as MEKK1-activated cJUN, and significantly ( $\left.p=2,84466 \times 10^{-5 * * * *}\right)$ when compared to FOXA1. The co-transfection of Mekk1, cJun, and Foxa1 caused a further significant upregulation of the reporter activity compared to cJUN ( $\left.p=0.004115^{* *}\right)$, cJUN + MEKK1 $\left(p=0.0002307^{* * *}\right)$, and Foxa1 $\left(p=3.37212 \times 10^{-10 * * * *}\right)$. These data indicated a positive interaction between FOXA1 and cJUN in the transcriptional activation of Odf2 that is reinforced by MEKK1-mediated activation of cJUN. The co-expression of all four factors, MEKK1, cJUN, C/EBP $\alpha$, and FOXA1 did not significantly increase the reporter gene activity compared to the co-expression of these factors but without FOXA1. The combination of FOXA1 with cJUN and C/EBP $\alpha$ did not cause an up-regulation of reporter gene activity as compared to FOXA1 alone.

Since cilia formation is stimulated by serum starvation-induced cellular quiescence simultaneously with enhanced Odf2 promoter activity [54] we wondered whether FOX TFs are also activated by serum starvation. The reporter gene experiment was therefore modified in that the medium was exchanged for serum-deprived medium 24 hrs post-transfection and cells cultivated for another $48 \mathrm{hrs}$ before harvesting for luciferase assay. A significant increase in reporter gene activity was not observed neither for any of the transcription factors FOXO3A, FOXO1, FOXJ, or FOXJ together with RFX3, nor for the constitutive active FOXO1, FOXO1ADA (Fig. 2B). In contrast, a significant increase was found for FOXA1 compared to the control (2.2$\left.p G L 3+p h R L ; p=0.000041^{* * * *}\right)$. Increased reporter gene activity was also observed by coexpression of FOXA1 and C/EBPa when compared to the control (2.2-pGL3+phRL; $\left.\mathrm{p}=3.69035 \times 10^{-9 * * * *}\right)$, or to $\mathrm{C} / \mathrm{EBP} \alpha\left(\mathrm{p}=1.54407 \times 10^{-5 * * *}\right)$ but not when compared to FOXA1. Significant activation of the reporter compared to the control $(2.2-p G L 3+p h R L)$ was observed by co-expression of FOXA1 and MEKK1 $\left(p=0.003581^{* *}\right)$ but not when compared to FOXA1 
indicating that MEKK1 did not affect FOXA1. Co-expression of MEKK1, cJUN, and FOXA1 caused a strong upregulation of the Odf2 promoter compared to the control (2.2-pGL3+phRL; $\left.p=3.18068 \times 10^{-12 * * * *}\right)$, to cJUN+MEKK1 $\left(p=0.0003696^{* * *}\right)$, to MEKK1+FOXA1 $\left(p=0.00084057^{* * *}\right)$, or to FOXA1 $\left(p=0.0009507^{* * *}\right)$ indicating an effect of MEKK1-activated cJUN and its putative positive interaction with FOXA1 on the activity of the Odf2 promoter that was also observed in cycling cells (Fig. 2A).

To further verify FOXA1 as a transcriptional activator of the Odf2 promoter, the reporter vector 2.2-pGL3 was co-transfected with the Foxa1 expression plasmid, and either the negative control siRNA duplex, or one of the Foxa1 siRNA duplexes A, B, or C. The activities of the firefly luciferase reporter and the Renilla luciferase as the internal control were measured either 24 hrs post-transfection (cycling cells), or after 48 hrs cultivation in serum starvation medium (cell cycle-arrested cells). Calculation of the relative luminescence revealed an approximately 2.5 -fold increase of the reporter gene activity when expression of FOXA1 was enforced compared to control cells in which only the reporter 2.2-pGL3 and the internal control phRL were co-transfected (Fig. 3). Co-transfection of the negative control siRNA did not significantly change the expression of the reporter vector. However, co-transfection of either one out of three Foxa1 siRNA duplexes revealed reduced activity of the reporter vector, especially when cells were serum-starved. Significant reductions in reporter gene activity $\left(p^{*}\right)$ were obtained for the Foxa1 siRNA duplex $C$ in cycling cells $\left(p=0.03953205^{*}\right)$ as well as in quiescent cells $\left(p=0.0142835^{*}\right)$, indicating that the siRNA $C$ is the most effective. Since Foxa1 siRNA duplexes efficiently inhibit FOXA1-mediated activation of the Odf2 promoter these data demonstrate the importance of FOXA1 for the transcriptional activation of Odf2, as well as the specificity of Foxa1 siRNA duplexes for the knockdown of FOXA1.

\section{FOXA1 binds to the Odf2 promoter}

Reporter gene assays were performed to narrow down the binding site of FOXA1 in the Odf2 promoter. Fragments of the Odf2 promoter, cloned upstream of the firefly reporter gene in pGL3 as described in Pletz et al. [54], were investigated for their responsiveness to the FOXA1 transcription factor. Here, FOXA1-induced transcriptional activation was related to the basal level of the respective reporter construct without Foxa1 co-transfection. Strong induction of transcription was observed for the promoter region -1282 to -1805 in clone 7.6 ( 70x when 
co-transfected with Foxa1 as compared to the control without FOXA1 overexpression), for the region -1368 to -1805 in clone 22.1 ( $\sim 16 \mathrm{x}$ ), and the region -94 to -1805 in clone 7.1 ( $\sim \mathrm{x}$ ) (Fig. $4 \mathrm{~A})$, indicating that the FOXA1-binding site most likely is located in the region between -1282 to -1805 of the Odf2-promoter.

A sequence (TGTTTAC) with similarity to the FOXA1 consensus binding sequence T(G/A)TT(T/G)AC [64] was identified in the Odf2 promoter at position -1768 to - 1775 upstream of the transcription start site. To investigate the binding of FOXA1 to this sequence we performed chromatin immune-precipitation using the Odf2-promoter reporter vector 2.2pGL3 as bait and the anti-FOXA1 antibody as the fishing agent. Furthermore, ChIP was additionally performed in cells co-transfected with the Foxa1 expression plasmid. Enrichment of the binding sequence was investigated by qPCR using primers that flank the supposed binding site and obtained $\mathrm{Ct}$-values were adjusted to the input $(\Delta \mathrm{Ct})$, and the control $\Delta \mathrm{Ct}$ values $(\Delta \Delta \mathrm{Ct})$. We found $\sim 26 \mathrm{x}$ enrichment of the binding site in cells co-transfected with the Foxa1 expression plasmid $\left(p<0.01^{* *}\right)$, and $\sim 4 x$ enrichment when the endogenous FOXA1 was precipitated ( $p=0.137344$, Student's T-test two-tailed, homoscedastic) (Fig. 4 B). No enrichment was found for the sequence of the putative DREAM binding site (not shown) indicating the specificity of FOXA1-binding. Although precipitation of the endogenous FOXA1 did not reveal significant enrichment of the target sequence compared to the control IgGs, coexpression of FOXA1 together with the Odf2-reporter 2.2-pGL3 as bait resulted in a significant enrichment of the target sequence. These results indicated that the binding site of FOXA1 in the Odf2 promoter is represented by the sequence TGTTTAC situated at position - 1768 to 1775 upstream of the transcription start site.

\section{Expression of Fox transcription factors in NIH3T3 cells}

Our data indicated FOXA1 as an activator of Odf2 transcription in NIH3T3 fibroblasts. However, it was unknown whether Foxa1 or any other TF of the Fox-family is indeed expressed in NIH3T3 cells. We, therefore, verified the expression of Fox TFs by RT-PCR using CDNA prepared from NIH3T3 cells. Although no products were present after the first RT-PCR round, a nested PCR reaction using the first RT-PCR reaction as the template, revealed products of the expected lengths for all Fox TFs investigated (Fig. 5A). The correct amplifications were verified by sequencing PCR products. Thus, all four transcription factors investigated, Foxa1, Foxo1, 
Foxo3a, and Foxj, were expressed in NIH3T3 cells albeit at a low level. Furthermore, the endogenous FOXA1 was detected immunologically inside the nuclei showing a speckled appearance that colocalized with nucleoli (Fig. 5B, a and c).

\section{Efficient down-regulation of FOXA1 by Foxa1 siRNA}

We have demonstrated that Foxa1 siRNA duplexes inhibit FOXA1-mediated activation of the Odf2 promoter in reporter gene assays. To further prove that this effect is caused by siRNAmediated knockdown of FOXA1, quantitative analyses were performed. Because of the low level expression of Foxa1, we used FOXA1::GFP overexpression by co-transfection of Foxa1::gfp with either the control siRNA, or one out of the three Foxa1 siRNA duplexes A, B, or C. Proteins were analysed by quantitative Western blotting using anti-FOXA1 antibodies, and anti- $\alpha$-Tubulin antibodies (Fig. 6A, FOXA1 in green, $\alpha$-Tubulin in red). Signal intensities were quantified and the FOXA1 intensity related to the intensity of $\alpha$-Tubulin in the same lane. The obtained relative intensities were related to the average relative intensity of the control siRNA samples giving the fold change of expression. We observed an efficient reduction of FOXA1::GFP by Foxa1 siRNA duplexes B, or C, whereas no reduction was observed with the Foxa1 siRNA A when compared to the control siRNA duplexes (Fig. 6B, $p<0.01 * *$ ).

\section{Foxa1 siRNA-mediated knockdown affects the endogenous expression of Foxa1, Odf2/ODF2, and CP110}

Having proven an efficient reduction of FOXA1 protein by Foxa1 siRNA-mediated knockdown, we asked whether knockdown of Foxa1 could also be detected at the endogenous transcript level and whether a knockdown of FOXA1 would be accompanied by a reduction of Odf2 transcripts and also of ODF2 proteins. NIH3T3 cells were, thus, transfected with the Foxa1 siRNA, and transcripts of Foxa1 and Odf2 were quantified by qRT-PCR. We observed a reduction of Foxa1 transcripts in Foxa1 siRNA-transfected cells to $\sim 0.5 \mathrm{x}$ of that in control siRNA-transfected cells (Fig. 7A, p** 0.00413455). Furthermore, the reduction of Foxa1 transcripts was accompanied by a reduction of Odf2 transcripts to $\sim 0.6 \mathrm{x}$ compared to control siRNA-transfected cells (Fig. 7A; $\mathrm{p}^{* * * *} 2.0216 \times 10^{-6}$ ). These results, therefore, indicate that transcription of Odf2 is under control of FOXA1. 
Finally, we quantified ODF2 proteins in lysates obtained from cells transfected with either the control siRNA, or one of the Foxa1 siRNA duplexes. We observed a significant reduction of ODF2 to approximately $0.6 \mathrm{x}$ when FOXA1 was knocked down by Foxa1 siRNA C $\left(p=0.000631^{* * *}\right)$ (Fig. 7B, C; p). Additionally, FOXA1 knockdown caused also a significant reduction of CP110, which has been annotated as a target gene of FOXA1 (Rouillard et al., 2016) (Fig. 7D, E p=0.002232**).

\section{FOXA1 is necessary for primary cilia formation}

Since the amount of ODF2 is crucial for primary cilia generation we asked whether FOXA1 is involved in cilia formation. NIH3T3 cells were transfected with either one of the three different siRNA duplexes (SR415184A, SR415184B, or SR415184C) or the scrambled negative control siRNA duplex. 24 hrs post-transfection the medium was exchanged for serum starvation medium to induce cilia formation, and cells were cultivated for another $24 \mathrm{hrs}$ or $48 \mathrm{hrs}$. Primary cilia were then decorated for ARL13B and manually counted. siRNA-mediated knockdown of FOXA1 caused a reduction of primary cilia to $\sim 0.8 \mathrm{x}$ when cultivated in serum starvation medium for $24 \mathrm{hrs}\left(\mathrm{p}<0.05^{+}\right.$or $\left.\mathrm{p}<0.01^{++}\right)$. Cultivation in serum starvation medium for 48 hrs caused a reduction of primary cilia to $\sim 0.8 x$ by Foxa1 siRNA A $\left(p<0.05^{*}\right)$ and $\sim 0.5 x$ in Foxa1 siRNA B or C transfected cells (both $\mathrm{p}<0.01^{* *}$ ) (Fig. 8). Our results thus indicate that FOXA1 is mandatory for the formation of primary cilia.

\section{Co-immune precipitation revealed no direct interaction between FOXA1 and cJUN}

Our data demonstrated that FOXA1 is a transcriptional activator of Odf2. Furthermore, reporter gene assays suggested a positive interaction between FOXA1 and cJUN. To verify, we transfected cells with expression plasmids either Foxa1::gfp or Foxa1::gfp and Mekk1, followed by capturing of FOXA1::GFP using immobilized anti-GFP antibodies. Although FOXA1::GFP (of $77 \mathrm{kDa}$ ) was successfully captured, demonstrated by its presence in the eluate of the bead-bound fraction, neither cJUN nor MEKK1-phosphorylated cJUN of either 36-39 kDa or 42-45 kDa, respectively, were co-precipitated (Fig. 9A). Thus, neither the unphosphorylated (Fig. 9 A, B) nor the phosphorylated cJUN (Fig. 9A) were found to directly 
interact with FOXA1, despite FOXA1::GFP and cJUN colocalised in the nuclei of NIH3T3 cells (Fig. 9C). 


\section{Discussion}

Primary cilia are essential sensory organelles present on nearly all cells of the body. They are built in a cell cycle-dependent manner and are mainly found in quiescent cells. Generation of primary cilia depends on a crucial amount of ODF2/Cenexin, a basal body protein mandatory for cilia formation and viability [51-53]. Transcription of Odf2 is cell cycle-dependent with upregulation in serum-starved cells and thus correlated with primary cilia formation [54]. We have previously identified TFs controlling transcription of Odf2 [54, 55]. However, core TFs regulating the formation of primary cilia have still to be identified. Motile ciliogenesis is controlled by the master regulator FOXJ1 in cooperation with RFX factors $[44,65,66]$. Odf2 was not annotated as a direct target gene of FOXJ1 and neither RFX3 nor FOXJ1 TFs activate transcription of $\operatorname{Odf2}[46,54]$. Furthermore, opposed to multiciliogenesis primary ciliogenesis is FOXJ1-independent [67].

FOXJ1 belongs to the large family of evolutionarily conserved forkhead-box (Fox) TFs that have diverse functions in development and differentiation. FOX TFs are characterised by the conserved DNA-binding domain of $~ 110 a a$, denoted as fork head domain, first identified in FKH and the rat hepatocyte-enriched transcription factor HNF-3A [35, 36]. Currently, more than 44 genes were annotated in both, mouse and humans, and categorized into subclasses A to S. FOX proteins are essential TFs as the deletion of just one Fox gene very often leads to lethality, and mutations in Fox genes are associated with developmental disorders or diseases $(40,68]$. FOXJ1, alias HFH4, is the master regulator for motile cilia formation and is, therefore, essential for the execution of the specialized functions of epithelial cells harbouring motile cilia $[41,42]$.

The FOXO-proteins and FOXM1 function in cell cycle control. FOXM1 is a key regulator of both the $\mathrm{G} 1 / \mathrm{S}$ phase and $\mathrm{G} 2 / \mathrm{M}$ phase transition and is essential for proper mitotic progression [69]. Furthermore, FOXM1 is a component of the DREAM complex that inhibits transcription of target genes for cell proliferation in the quiescent state but promotes expression during the cell cycle [70]. The FOXO proteins are inhibitors of the cell cycle and regulate metabolism and lifespan. Like FOXM1 their activity is controlled by post-translational modifications. AKTmediated phosphorylation of FOXO proteins caused their inactivation by translocation into the cytoplasm where they are stabilized by interaction with 14-3-3 scaffolding proteins [29]. FOXO proteins regulate cell proliferation via up-regulation of the cell cycle inhibitor p27 KIP1 
and downregulation of cyclin D1 [71, 72]. Their function as cell cycle inhibitors suggested a causal relationship to the transcriptional regulation of primary cilia formation, which are mainly found in quiescent cells. We focused on the sub-distal appendage protein and marker of the mother centriole and the basal body, ODF2/Cenexin, because it is mandatory for cilia formation and transcriptionally upregulated in serum-starved, cell-cycle arrested cells [51-56]. A consensus binding sequence for the forkhead-box TFs FOXO and FOXA1 were identified in the promoter region of the mouse Odf2-gene $[63,64]$. However, neither FOXO1 nor its constitutively active form FOXO1ADA, nor FOXO3A activated transcription of Odf2 in reporter gene assays. These data indicated that FOXO TFs are most unlikely transcriptional activators of Odf2 and eventually regulators of primary ciliation. Instead, we found significant transcriptional activation of Odf2 by FOXA1.

The mammalian FOXA TFs were first identified in the rat liver and hence named hepatocyte nuclear factor 3 (HNF3) $\alpha, \beta$, and $\gamma$, respectively FOXA1, 2, and 3 [73]. Expression of FOXA1, FOXA2, and FOXA3 during development and in adult tissues exhibit overlapping but also distinct patterns [40]. Furthermore, FOXA1 is more widely expressed in adult tissues than FOXA2 [40]. Foxa1-deficient mice survive until after birth but die between P2 (postnatal day 2 ) and P12 due to hypoglycemia and defects in kidney function [74, 75]. FOXA2 is essential for node and notochord formation causing defects in the dorsal-ventral patterning of the neural tube and embryonic lethality when absent $[76,77]$. FOXA1 and FOXA2 regulate positively and negatively Sonic hedgehog (Shh)-signalling, via transcriptional regulation of the downstream effector Gli2, to specify the ventral midbrain progenitor identity [78]. FOXA3 is specifically expressed in the testis, in Leydig cells, and spermatids, and FOXA3-deficiency affected male fertility in mice [79]. Deletion of either one of these FOXA-factors in mice revealed that FOXA1 and FOXA2 can compensate for each other and that even FOXA3 may compensate for the deletion of both, FOXA1 and FOXA2, in late gestation in mice [80].

The FOXA TFs enable the access of tissue-specific TFs to their binding site and have, therefore, been denominated as 'pioneer factors' $[80,81]$. Furthermore, they bookmark temporarily shut-off genes for easy reactivation [82]. Their function as pioneer factors has been annotated to the structural similarity of the forkhead box to histones $\mathrm{H} 1$ and $\mathrm{H} 5$ [83, 84]. Our reporter gene assays indicated a cross-talk between FOXA1 and cJUN, especially MEKK1-activated cJUN, in the transcriptional activation of Odf2. However, we could not find a direct interaction 
between FOXA1 and cJUN. Thus, the binding of FOXA1 to the Odf2 promoter might enable concurrent binding of cJUN or phosphorylated cJUN to increase the expression of Odf2 corroborating its function as a pioneer factor.

To the known tasks of FOX TFs our data add the novel function in the regulation of primary cilia formation. We have shown that FOXA1 binds to its consensus sequence in the mouse Odf2 promoter and activates the expression of Odf2/ODF2. Knockdown of FOXA1 not only downregulated Odf2 transcripts and ODF2 proteins but also inhibited primary cilia formation. We found a significant reduction of Foxa1 (to $\sim 0.5 \mathrm{x}$ ) as well as Odf2 transcripts (to $\sim 0.6 \mathrm{x}$ ) after transfection of Foxa1 siRNA that correlated with a 0.6 -fold decrease in ODF2 proteins. Since Foxa1 siRNA caused only a knockdown of FOXA1 but could not completely abolish it, FOXA1 is still present and, in addition to a putative compensatory mechanism of FOXA2, contributed to the continued expression of ODF2. Foxa2 is also transcribed in NIH3T3 cells as was observed by nested RT-PCR (Supplementary Fig. S1). Reduced expression of ODF2 by FOXA1 knockdown provoked a reduction in ciliated cells up to $0.55-0.75 x$ (Fig. 8) compared to their reduction to 0.3-0.47x when Odf2 was knocked down (all related to their respective controls) (Fig. 1). Our results, thus, demonstrate that Odf2 is a target gene of FOXA1 that positively regulated its transcription. Consequently, based on the availability of the ODF2 protein and further ciliary proteins, the generation of primary cilia is regulated by FOXA1. The ChIP-seq dataset from the ENCODE Transcription Factor Targets Datasets lists several ciliary genes as FOXA1 target genes, in between the 'Gold Standard' ciliary genes including Odf2, CCP110/CP110, Cep290, Cep250, Cep164, Cep135, and the Bardet-Biedl-Syndrome genes BBS1, BBS4, BBS9, BBS10, and $B B S 12$, and many more ciliary genes [85-87]. These data indicate that FOXA1 is a TF for several ciliary genes and thus a regulator of ciliogenesis. To further corroborate, we demonstrated that CP110 is also affected by FOXA1 knockdown, which is, therefore, a FOXA1 target gene as indicated in the ChIP-seq dataset.

FOXA TFs are widely expressed during mouse embryogenesis and are required for the normal development of the nervous system and endoderm-derived organs. Their expression is even maintained in several adult tissues [75]. FOXA1 and FOXA2 TFs contribute to the maintenance of epithelial cell identity and their deregulated expression is associated with cancer formation [88-91]. FOXA1/2 are important for Sonic hedgehog (SHH) signalling by restricting the expression of the transcriptional mediators, Gli1 and Gli2 [78, 92, 93]. The hedgehog pathway 
is essential for vertebrate development, and aberrant activation of the pathway is associated with cancer formation [94]. Furthermore, the hedgehog signal transduction pathway is strictly dependent on the primary cilium [95]. The primary cilium is involved in both, promoting and inhibiting tumorigenesis likewise as was described for deregulated FOXA expression, but is generally missing in cancer cells $[89,96,97]$. The data, thus, indicated a link between FOXA1 TF, and hedgehog signalling, finally culminating on the primary cilium. Our data indicated that FOXA1 regulates primary ciliogenesis, and suggested that the deregulated expression of FOXA1 in cancer cells affects the primary cilium, causing eventually aberrant hedgehog signalling. 


\section{Declarations}

\section{Consent for publication}

All authors have approved the final version of the manuscript and have given their consent for publication.

\section{Availability of data and material}

The datasets generated during and/or analysed during the current study are available from the corresponding author on reasonable request.

\section{Competing interests}

The authors have no relevant financial or non-financial interests to disclose.

\section{Financial and ethical statements}

The authors declare that no funds, grants, or other support were received during the preparation of this manuscript.

This is a cell culture-based study. No ethical approval is required.

\section{Author's contributions}

Material preparation, data collection and analyses were performed by Christian C. Czerny, Anett Borschel, Mingfang Cai, Madeline Otto and Sigrid Hoyer-Fender. Sigrid Hoyer-Fender designed the experiments, wrote the manuscript and prepared the figures. All authors commented on previous versions of the manuscript. All authors read and approved the final manuscript.

\section{Acknowledgments}

We thank our colleagues for the kind gift of plasmids, Kyung S. Lee (Bethesda) for hCenexin, Steven Brody (St. Louis) for Foxj, Walter Reith (Genf) for Rfx3, and Werner Albig and Detlef Doenecke (Göttingen) for human histone $H 4$. 


\section{References}

[1] Hoyer-Fender S (2013) Primary and motile cilia: Their Ultrastructure and Ciliogenesis. In Cilia and Nervous System Development and Function; Tucker, K.L., Caspary, T., Eds.; Springer Netherlands: Dordrecht; pp. 1-53 ISBN 978-94-007-5808-7

[2] Satir P, Christensen T (2007) Overview of structure and function of mammalian cilia. Annu Rev Physiol 69: 377-400

[3] Fisch C, Dupuis-Williams P (2011) Ultrastructure of cilia and flagella - back to the future! Biol Cell 103: 249-270

[4] Pazour GJ, Rosenbaum JL (2002) Intraflagellar transport and cilia-dependent diseases. Trends Cell Biol 12: 551-555

[5] Badano JL, Mitsuma N, Beales PL, Katsanis N (2006) The ciliopathies: an emerging class of human genetic disorders. Annu Rev Genomics Hum Genet 7: 125-148

[6] Fliegauf M, Benzing T, Omran H (2007) When cilia go bad: cilia defects and ciliopathies. Nat Rev Mol Cell Biol 8: 880-893

[7] Gerdes M, Davis EE, Katsanis N (2009) The vertebrate primary cilium in development, homeostasis, and disease. Cell 137: 32-45

[8] Veland IR, Awan A, Pedersen L, Yoder BK, Christensen ST (2009) Primary cilia and signalling pathways in mammalian development, health and disease. Nephron Physiol 111: 39-53

[9] Goetz SC, Anderson KV (2010) The primary cilium: a signalling center during vertebrate development. Nat Rev Genet 11: 331-344

[10] Reiter J, Leroux MR (2017) Genes and molecular pathways underpinning ciliopathies. Nat Rev Mol Cell Biol 18: 533-547

[11] Quarmby LM, Parker JDK (2005) Cilia and the cell cycle. J Cell Biol 169: 707-710

[12] Kim SK, Tsiokas L (2011) Cilia and cell cycle re-entry. Cell Cycle 10: 2683-2690

[13] Santos N, Reiter JF (2008) Building it up and taking it down: the regulation of vertebrate ciliogenesis. Dev Dynamics 237: 1972-1981

[14] Plotnikova OV, Pugacheva EN, Golemis EA (2009) Primary cilia and the cell cycle. Methods Cell Biol 94: 137-160

[15] Seeley ES, Nachury MV (2010) The perennial organelle: Assembly and disassembly of the primary cilium. J Cell Sci 123: 511-518

[16] Wheatley DN (1971) Cilia in cell-cultured fibroblasts. III. Relationship between mitotic activity and cilium frequency in mouse 3 T6 fibroblasts. J Anat 110: 367-382 
[17] Tucker RW, Pardee AB, Fujiwara K (1979) Centriole ciliation is related to quiescence and DNA synthesis in 3 T3 cells. Cell 17: 527-535

[18] Schlereth K, Weichenhan D, Bauer T, Heumann T, Giannakouri E, Lipka D, Jaeger S, Schlesner M, Aloy P, Eils R, Plass C, Augustin HG (2018) The transcriptomic and epigenetic map of vascular quiescence in the continuous lung endothelium. elife 7: e34423. DOI:10.7554/eLife.34423

[19] Malumbres M, Harlow E, Hunt T, Hunter T, Lahti JM, Manning G, Morgan DO, Tsai LH, Wolgemuth DJ (2009) Cyclin-dependent kinases: a family portrait. Nat Cell Biol 11: 1275-1276 [20] Lim S, Kaldis P (2013) Cdks, cyclins and CKIs: roles beyond cell cycle regulation. Development 140: 3079-3093. doi:10.1242/dev.091744

[21] Malumbres M (2014) Cyclin-dependent kinases. Genome Biol 15: 122

[22] Wang Z (2021) Regulation of cell cycle progression by growth factor-induced cell signaling. MDPI Cells 10: 3327. https://doi.org/10.3390/cells10123327

[23] Johnson DG, Walker CL (1999) Cyclins and cell cycle checkpoints. Annu Rev Pharmacol Toxicol 39: 295-312

[24] Sánchez I, Dynlacht BD (2005) New insights into cyclins, CDKs, and cell cycle control. Sem Cell \& Dev Biol 16: 311-321

[25] Carter ME, Brunet A (2007) FOXO transcription factors. Quick guide. Curr. Biol. 17: R114 [26] Biggs WH $3^{\text {rd }}$, Meisenhelder J, Hunter T, Cavenee WK, Arden KC (1999) Protein kinase B/Akt-mediated phosphorylation promotes nuclear exclusion of the winged helix transcription factor FKHR1. Proc Natl Acad Sci USA 96: 7421-7426

[27] Kops GJPL, Medema RH, Glassford J, Essers MAG, Dijkers PF, Coffer PJ, Lam EWF, Burgering BMT (2002) Control of cell cycle exit and entry by protein kinase B-regulated forkhead transcription factors. Mol Cell Biol 22: 2025-2036

[28] Greer EL, Brunet A (2005) FOXO transcription factors at the interface between longevity and tumor suppression. Oncogene 24: 7410-7425

[29] Tzivion G, Dobson M, Ramakrishnan G (2011) FoxO transcription factors: Regulation by AKT and 14-3-3 proteins. Biochim Biophys Acta 1813: 1938-1945

[30] Kops GJPL, Dansen TB, Polderman PE, Saarloos I, Wirtz KWA, Coffer PJ, Huang TT, Bos JL, Medema RH, Burgering BMT (2002) Forkhead transcription factor FOXO3a protects quiescent cells from oxidative stress. Nature 419: 316-321 
[31] Tothova Z, Kollipara R, Huntly BJ, Lee BH, Castrillon DH, Cullen DE, McDowell EP, LazoKallanian S, Williams IR, Sears C, Armstrong SA, Passegué E, DePinho RA, Gilliland DG (2007) FoxOs are critical mediators of hematopoietic stem cell resistance to physiologic oxidative stress. Cell 128: 325-339. https://doi.org/10.1016/i.cell.2007.01.003

[32] Zhang Y, Xing Y, Zhang L, Mei Y, Yamamoto K, Mak TW, You H (2012) Regulation of cell cycle progression by forkhead transcription factor FOXO3 through its binding partner DNA replication factor Cdt1. Proc Natl Acad Sci USA 109: 5717-5722

[33] Liang R, Ghaffari S (2017) Mitochondria and FOXO3 in stem cell homeostasis, a window into hematopoietic stem cell fate determination. J Bioenerg Biomembr 49: 343-346

[34] Lai E, Prezioso VR, Smith E, Litvin O, Costa RH, Darnell JE, Jr (1990) HNF-3A, a hepatocyteenriched transcription factor of novel structure is regulated transcriptionally. Genes Dev 4: $1427-1436$

[35] Weigel D, Jäckle H (1990) The fork head Domain: A novel DNA binding motif of eukaryotic transcription factors? Cell 63: 455-456

[36] Lai E, Prezioso VR, Tao W, Chen WS, Darnell JE, Jr (1991) Hepatocyte nuclear factor $3 \alpha$ belongs to a gene family in mammals that is homologous to the Drosophila homeotic gene fork head. Genes Dev 5: 416-427

[37] Jürgens G, Weigel D (1988) Terminal versus segmental development in the Drosophila embryo: The role of the homeotic gene fork head. Roux's Arch Dev Biol 197: 345-354

[38] Weigel D, Jürgens G, Küttner F, Seifert E, Jäckle H (1989) The homeotic gene fork head encodes a nuclear protein and is expressed in the terminal regions of the Drosophila embryo. Cell 57: 645-658

[39] Hosaka T, Biggs III W, Tieu D, Boyer AD, Varki NM, Cavenee WK, Arden KC (2004) Disruption of forkhead transcription factor (FOXO) family members in mice reveals their functional diversification. Proc Natl Acad Sci USA 101: 2975-2980. Doi: $10.1073 /$ pnas.0400093101

[40] Golson ML, Kaestner KH (2016) Fox transcription factors: from development to disease. Development 143: 4558-4570

[41] Chen J, Knowles HJ, Hebert JL, Hackett BP (1998) Mutation of the mouse hepatocyte nuclear factor/forkhead homolog 4 gene results in an absence of cilia and random left-right asymmetry. J Clin Invest 102: 1077-1082 
[42] Brody SL, Yan XH, Wuerffel MK, Song SK, Shapiro SD (2000) Ciliogenesis and left-right axis defects in forkhead factor HFH4-null mice. Am J Respir Cell Mol Biol 23: 45-51

[43] Thomas J, Morlé L, Soulavie F, Laurençon A, Sagnol S, Durand B (2010) Transcriptional control of genes involved in ciliogenesis : a first step in making cilia. Biol Cell 102 : 499-513. Doi :10.1042/BC20100035

[44] Choksi SP, Lauter G, Swoboda P, Roy S (2014) Switching on cilia: transcriptional networks regulating ciliogenesis. Development 141: 1427-1441. doi:10.1242/dev.074666

[45] Marshall CB, Mays DJ, Beeler JS, Rosenbluth JM, Boyd KL, Santos Guasch GL, Shaver TM, Tang LJ, Liu Q, Shyr Y, Venters BJ, Magnuson MA, Pietenpol JA (2016) P73 is required for multiciliogenesis and regulates the Foxj1-associated gene network. Cell Rep 14(10): 22892300. Doi: 10.1016/j.celrep.2016.02.035

[46] Mukherjee I, Roy S, Chakrabarti S (2019) Identification of important effector proteins in the FOXJ1 transcriptional network associated with ciliogenesis and ciliary function. Front Genet. https://doi.org/10.3389/fgene.2019.00023.

[47] Avidor-Reiss T, Maer AM, Koundakjian E, Polyanovsky A, Keil T, Subramaniam S, Zucker CS (2004) Decoding cilia function: defining specialized genes required for compartmentalized cilia biogenesis. Cell 117: 527-539

[48] Li JB, Gerdes JM, Haycraft CJ, Fan Y, Teslovich TM, May-Simera H, Li H, Blacque OE, Li L, Leitch CC, Lewis RA, Green JS, Parfrey PS, Leroux MR, Davidson WS, Beales PL, Guay-Woodford LM, Yoder BK, Stormo GD, Katsanis N, Dutcher SK (2004) Comparative genomics identifies a flagellar and basal body proteome that includes the BBS5 human disease gene. Cell 117: 541552

[49] Pedersen LB, Veland IR, Schroder JM, Christensen ST (2008) Assembly of primary cilia. Dev Dyn 237: 1993-2006

[50] Ishikawa H, Marshall WF (2011) Ciliogenesis: building the cell's antenna. Nat Rev Mol Cell Biol 12: 222-234

[51] Ishikawa H, Kubo A, Tsukita S, Tsukita S (2005) Odf2-deficient mother centrioles lack distal/subdistal appendages and the ability to generate primary cilia. Nat Cell Biol 7: 517-524 [52] Salmon NA, Reijo Pera RA, Xu EY (2006) A gene trap knockout of the abundant sperm tail protein, outer dense fiber 2, results in preimplantation lethality. Genesis 44: 515-522

[53] Anderson CT, Stearns T (2009) Centriole age underlies asynchronous primary cilium growth in mammalian cells. Curr Biol 19: 1498-1502 
[54] Pletz N, Medack A, Rieß EM, Yang K, Basir Kazerouni Z, Hüber D, Hoyer-Fender S (2013) Transcriptional activation of Odf2/Cenexin by cell cycle arrest and the stress activated signaling pathway (JNK pathway). Biochim Biophys Acta 1833: 1338-1346

[55] Tylkowski MA, Yang K, Hoyer-Fender S, Stoykova A (2014) Pax6 controls centriole maturation in cortical progenitors through Odf2. Cell Mol Life Sci 72: 1795-1809. doi: 10.1007/s00018-014-1766-1 [56] Brohmann H, Pinnecke S, Hoyer-Fender S (1997) Identification and characterization of new cDNAs encoding outer dense fiber proteins of rat sperm. J Biol Chem 272: 10327-10332 [57] Soung NK, Kang YH, Kim K, Kamijo K, Yoon H, Seong YS, Kuo YL, Miki T, Kim SR, Kuriyama R, Giam CZ, Ahn CH, Lee KS (2006) Requirement of hCenexin for proper mitotic functions of polo-like kinase 1 at the centrosomes. Mol Cell Biol 26: 8316-8335

[58] Albig W, Doenecke D (1997) The human histone gene cluster at the D6S105 locus. Hum Genet 101: 284-294

[59] Laemmli UK (1970) Cleavage of structural proteins during assembly of the head of the bacteriophage T4. Nature 227: 680-685

[60] Towbin H, Staehelin T, Gordon J (1979) Electrophoretic transfer of proteins from polyacrylamide gels to nitrocellulose sheets: procedure and some applications. Proc Natl Acad Sci USA 76: 4350-4354

[61] Denissov S, van Driel M, Voit R, Hekkelman M, Hulsen T, Hernandez N, Grummt I, Wehrens $\mathrm{R}$, Stunnenberg H (2007) Identification of novel functional TBP-binding sites and general factor repertoires. EMBO J 26: 944-954

[62] Yang, K., Tylkowski, M.A., Hüber, D., Tapia Contreras, C., Hoyer-Fender, S. (2018). ODF2/Cenexin maintains centrosome cohesion by restricting ß-catenin accumulation. J Cell Sci 131, jcs220954, doi:10.1242/jcs.220954

[63] Hedrick SM, Michelini RH, Doedens AL, Goldrath AW, Stone EL (2012) FOXO transcription factors throughout T cell biology. Nature Reviews Immunology 12: 649-661

[64] Bochkis IM, Schug J, Ye DZ, Kurinna S, Stratton SA, Barton MC, Kaestner KH (2012) Genome-wide location analysis reveals distinct transcriptional circuitry by paralogous regulators Foxa1 and Foxa2. PLoS Genetics 8(6): e1002770. doi:10.1371/journal.pgen.1002770

[65] You Y, Huang T, Richer EJ, Schmidt JE, Zabner J, Borok Z, Brody SL (2004) Role of f-box factor foxj1 in differentiation of ciliated airway epithelial cells. Am J Physiol 286: L650-L657 
[66] El Zein L, Ait-Lounis A, Morlé L, Thomas J, Chhin B, Spassky N, Reith W, Durand B (2009) RFX3 governs growth and beating efficiency of motile cilia in mouse and controls genes involved in human ciliopathies. J Cell Sci 122: 3180-3189

[67] Jain R, Pan J, Driscoll JA, Wisner JW, Huang T, Gunsten SP, You, Y, Brody SL (2010) Temporal relationship between primary and motile ciliogenesis in airway epithelial cells. Am J Respir Cell Mol Biol 43: 731-739. DOI:10.1165/rcmb.2009-03280C

[68] Hannenhalli S, Kaestner KH (2009) The evolution of Fox genes and their role in development and disease. Nat Rev Genet 10: 233-240

[69] Laoukili J, Kooistra MRH, Brás A, Kauw J, Kerkhoven RM, Morrision A, Clevers H, Medema $\mathrm{RH}$ (2005) FoxM1 is required for execution of the mitotic program and chromosome stability. Nat Cell Biol 7: 126-136

[70] Chen X, Muller GA, Quass M, Fischer M, Han N, Stutchbury B, Sharrocks AD, Engeland K (2013) The forkhead transcription factor FOXM1 controls cell cycle-dependent gene expression through an atypical chromatin binding mechanism. Mol Cell Biol 33: 227-236

[71] Medema RH, Kops GJ, Bos JL, Burgering BM (2000) AFX-like forkhead transcription factors mediate cell-cycle regulation by Ras and PKB through p27kip1. Nature 404: 782-787

[72] Schmidt M, Fernandez de Mattos S, van der Horst A, Klompmaker R, Kops GJPL, Lam EWF, Burgering BMT, Medema RH (2002) Cell cycle inhibition by FoxO forkhead transcription factors involves downregulation of cyclin D1. Mol Cell Biol 22: 7842-7852

[73] Costa RH, Grayson DR, Darnell JE, Jr (1989) Multiple hepatocyte-enriched nuclear factors function in the regulation of transthyretin and alpha 1-antitrypsin genes. Mol Cell Biol 9: 14151425

[74] Behr R, Brestelli J, Fulmer JT, Miyawaki N, Kleyman TR, Kaestner KH (2004) Mild nephrogenic diabetes insipidus caused by Foxa deficiency. J Biol Chem 2769: 41936-41941

[75] Friedman JR, Kaestner KH (2006) The Foxa family of transcription factors in development and metabolism. Cell Mol Life Sci 63: 2317-2328

[76] Weinstein DC, Ruiz I Altaba A, Chen WS, Hoodless P, Prezioso VR, Jessell TM, Darnell JE, Jr (1994) The winged-helix transcription factor HNF-3 beta is required for notochord development in the mouse embryo. Cell 78: 575-588

[77] Ang SL, Rossant J (1994) HNF-3ß is essential for node and notochord formation in mouse development. Cell 78: 561-574 
[78] Mavromatakis YE, Lin W, Metzakopian E, Ferri ALM, Yan CH, Sasaki H, Whisett J, Ang SL (2011) Foxa1 and Foxa2 positively and negatively regulate Shh signalling to specify ventral midbrain progenitor identity. Mech Dev 128: 90-103

[79] Behr R, Sackett SD, Bochkis IM, Le PP, Kaestner KH (2007) Impaired male fertility and atrophy of seminiferous tubules caused haploinsufficiency for Foxa3. Dev Biol 306: 636-645

[80] Iwafuchi-Doi M, Zaret KS (2016) Cell fate control by pioneer transcription factors. Development 143: 1833-1837

[81] Cirillo LA, Lin FR, Cuesta I, Friedman D, Jarnik M, Zaret KS (2002) Opening of compacted chromatin by early developmental transcription factors HNF3 (FoxA) and Gata-4. Mol Cell 9: 279-289

[82] Caravaca JM, Donahue G, Becker JS, He X, Vinson C, Zaret KS (2013) Bookmarking by specific and nonspecific binding of Foxa1 pioneer factor to mitotic chromosomes. Genes Dev 27: $251-260$

[83] Clark KL, Halay ED, Lai E, Burley SK (1993) Co-crystal structure of the HNF-3/fork head DNA-recognition motif resembles histone H5. Nature 364: 412-420

[84] Zaret KS, Caravaca JM, Tulin A, Sekiya T (2010) Nuclear mobility and mitotic chromosome binding: similarities between pioneer transcription factor FoxA and linker histone H1. Cold Spring Harb Symp Quant Biol 75: 219-226

[85] vanDam TJP, Wheway G, Slaats GG, SYSCILIA Study Group, Huynen M, Giles RH (2013) The SYSCILIA gold standard (SCGSv1) of known ciliary components and its applications within a systems biology consortium. Cilia 2(7). http://www.ciliajournal.com/contetn/2/1/7

[86] vanDam et al (2019) CiliaCarta: An integrated and validated compendium of ciliary genes. PLoSOne 14(5): e0216705. https://doi.org/10.1371/journal.pone.0216705

[87] Rouillard AD, Gundersen GW, Fernandez NF, Wang Z, Monteiro CD, McDermott MG, Ma'ayan A (2016) The harmonizome: a collection of processed datasets gathered to serve and mine knowledge about genes and proteins. Database (Oxford). 2016 Jul 3;2016. pii: baw100 [88] Tang Y, Shu G, Yuan X, Jing N, Song J (2011) FOXA2 functions as a suppressor of tumor metastasis by inhibition of epithelial-to-mesenchymal transition in human lung cancers. Cell Res 21: 316-326

[89] Bernardo GM, Keri RA (2012) FOXA1: a transcription factor with parallel functions in development and cancer. Biosci Rep 32: 113-130. Doi:10.1042/BSR20110046 
[90] Zhang Z, Yang C, Gao W, Chen T, Qian T, Hu J, Tan Y (2015) FOXA2 attenuates the epithelial to mesenchymal transition by regulating the transcription of E-cadherin and ZEB2 in human breast cancer. Cancer Lett 361: 240-250

[91] Paranjapye A, Mutolo MJ, Ebron JS, Leir SH, Harris A (2020) The FOXA1 transcriptional network coordinates key functions of primary human airway epithelial cells. Am J Physiol Lung Cell Mol Physiol 319: L126-L136

[92] Epstein DJ, McMahon AP, Joyner AL (1999) Regionalization of Sonic hedgehog transcription along the anteroposterior axis of the mouse central nervous system is regulated by Hnf3-dependent and -independent mechanisms. Development 126: 281-292

[93] Filosa S, Rivera-Perez JA, Gomez AP, Gansmuller A, Sasaki H, Behringer RR, Ang SL (1997) Goosecoid and HNF-3beta genetically interact to regulate neural tube patterning during mouse embryogenesis. Development 124: 2843-2854

[94] Pasca di Magliano M, Hebrok M (2003) Hedgehog signalling in cancer formation and maintenance. Nat Rev Cancer 3: 903-911

[95] Bangs F, Anderson KV (2017) Primary cilia and mammalian hedgehog signaling. Cold Spring Harb Perspect Biol 9: a028175

[96] Higgins M, Obaidi I, McMorrow T (2019) Primary cilia and their role in cancer. Oncology Lett 17: 3041-3047

[97] Fabbri L, Bost F, Mazure NM (2019) Primary cilium in cancer hallmarks. Int J Mol Sci 20: 1336. Doi:10.3390/ijms20061336 


\section{Figure Legends}

Fig. 1 ODF2 is essential for primary cilia formation. A) NIH3T3 cells were transfected with histone H4::gfp (b, green) and decorated for primary cilia with anti-ARL13B staining (a, red). Nuclei were stained with DAPI (c, blue), and the merged image is shown in d. Scale bars in a-d of $10 \mu \mathrm{m}$. B) Manual counting of primary cilia exclusively in transfected cells, which are positive for H4::GFP, revealed a strong decrease when Odf2 was knocked down by transfection of either the short hairpin plasmid sh3 or Odf2 siRNA compared to the controls, $\mathrm{KO7}$ or control siRNA, respectively. Co-transfection of the non-targeted hCenexin with either sh3 or Odf2 siRNA rescued primary cilia formation. Student's T-test (one-tailed, homoscedastic): $p<0.05 *$ or ${ }^{+}, \mathrm{p}<0.01 * *$ or ${ }^{++}, \mathrm{p}<0.001 * * *$ or ${ }^{+++}$. Symbols represent comparison to either the respective controls (KO7 or control siRNA) * or to the respective knockdown (sh3 or Odf2 siRNA) +. Always biological triplicates with a total of $n$ counted cells: $K 07 n=1,621, \operatorname{sh} 3 n=1,591$, sh3+hCenexin $n=1,593$, control siRNA $n=1,509$, Odf2 siRNA $n=1,538$, Odf2 siRNA+hCenexin $n=1,580$. Pvalues: $\operatorname{sh} 3$ to K07: $p=0.000114^{* * *}$, sh3+hCenexin to $\operatorname{sh} 3 \mathrm{p}=0.000989^{+++}$, Odf2 siRNA to control siRNA $p=0.022857^{*}$, and Odf2 siRNA+hCenexin (rescue) to Odf2 siRNA $p=0.005358^{++}$.

Fig. 2 FOXA1 is a transcriptional activator of the Odf2-promoter. Co-expression of transcriptional activators, FOXO1, FOXO3A, FOXA1, FOXJ, RFX3, C/EBP $\alpha$, MEKK1, or cJUN with the firefly luciferase reporter under control of the Odf2 promoter, 2.2-pGL3, indicated FOXA1 as a transcriptional activator in cycling cells (A) and serum-starved cells (B), and suggested interaction between FOXA1 and cJUN. The firefly luciferase activity was related to the Renilla luciferase activity (encoded by $p h R L$ ) as internal control and the fold changes of activity were calculated using the average of the relative luminescence of the control (2.2-pGL3/phRL) as $100 \%$ (or 1). Measurements of reporter gene activities were always performed in biological triplicates per experiment using a total of $n$ biological replicates in cycling cells: $n=26$ (control, 2.2-pGL3), n=24 (FOXO3A), n=33 (FOXO1), n=36 (FOXA1), n=9 (FOXJ), n=6 (FOXJ+RFX3), n=15 (C/EBP $\alpha), n=9$ (C/EBP $\alpha+F O X A 1), n=6$ (C/EBP $\alpha+$ MEKK1), n=9 (MEKK1), n=9 (MEKK1 + FOXA1), $\mathrm{n}=9($ FOXA1 + cJUN), $\mathrm{n}=6$ (cJUN), $\mathrm{n}=18(\mathrm{cJUN}+$ MEKK1), $\mathrm{n}=12(\mathrm{cJUN}+$ MEKK1 +FOXA1), $\mathrm{n}=6$ $($ MEKK1 + cJUN + C/EBP $\alpha), n=6($ MEKK1 + cJUN +C/EBP $\alpha+F O X A 1), n=6(c J U N+C / E B P \alpha+$ FOXA1), and in serum-starved cells: $\mathrm{n}=18$ (control, 2.2-pGL3), $\mathrm{n}=18$ (FOXO3A), $\mathrm{n}=18$ (FOXO1), $n=3$ (FOXO1ADA), n=18 (FOXA1), n=9 (FOXJ), n=3 (FOXJ+RFX3), n=9 (C/EBP $\alpha), n=3$ (C/EBP $\alpha+$ 
FOXA1), $n=6$ (MEKK1), $n=6$ (MEKK1 + FOXA1), $n=6$ (MEKK1 + cJUN), $n=3$ (cJUN +MEKK1 +FOXA1). Student's T-test two-tailed, homoscedastic $\mathrm{p}<0.05 *, \mathrm{p}<0.01 * *, \mathrm{p}<0.001 * * *$, $\mathrm{p}<0.0001 * * * *$. Calculation of T-test to the control $(2.2-p G L 3 / p h R L) *$ or to Foxa1 cotransfection ${ }^{+}$.

Fig. 3 siRNA-mediated knockdown of Foxa1 inhibits FOXA1-mediated activation of the Odf2 promoter. Overexpression of FOXA1 (+ FOXA1) induced transcriptional upregulation of the firefly luciferase reporter controlled by the Odf2 promoter (2.2-pGL3) compared to the control (2.2-pGL3 + phRL) in both cycling cells and serum-starved cells. Co-transfection of the scrambled non-target siRNA (+ FOXA1 + control siRNA) did not significantly change the activity of the firefly luciferase. Co-transfection of either one of the three Foxa1 siRNA duplexes (+ FOXA1 + Foxa1 siRNA A, B, or C, respectively) repressed activation of the reporter vector in both cycling cells and serum-starved cells. Significant transcriptional repression by Foxa1 siRNA C (in cycling cells: $p=0.039532 *$, in serum-starved cells: $p=0.014283^{*}$, Student's T-test, two-tailed, homoscedastic). Three biological replicates each.

Fig. 4 FOXA1 binds to the sequence TGTTTAC situated at position -1768 to -1775 of the Odf2 promoter. A) Reporter gene assay to narrow down the FOXA1-binding site. Reporter vectors comprising specific parts of the Odf2 promoter were investigated for their activation by FOXA1. FOXA1-mediated transcriptional activation was always related to that of the respective vector, without FOXA1 co-expression. The strongest activation was observed for the reporter vectors $7.6(\sim 70 \mathrm{x}), 22.1(\sim 16 \mathrm{x})$, and $7.1(\sim 4 \mathrm{x})$ indicating that the FOXA1-binding site is positioned in the region -1282 to -1805 . Three biological replicates. B) Chromatin immune-precipitation by FOXA1 and qPCR of the binding-site sequence revealed significant enrichment. NIH3T3 cells were transfected with the Odf2 promoter reporter vector 2.2-pGL3 as bait. Co-transfection of the Foxa1 expression plasmid (Foxa1+2.2-pGL3/anti-FOXA1) resulted in an $\sim 26 x$ enrichment of the FOXA1-binding site compared to the control IgGs (Foxa1+2.2-pGL3/control IgG) ( $\left.p^{* *}, p=0.007838\right)$. Precipitation of the endogenous FOXA1 by anti-FOXA1 antibodies (2.2-pGL3/anti-FOXA1) caused an $\sim 4 \mathrm{x}$ enrichment of the binding sequence compared to the control (2.2-pGL3/control IgG) that is, however, not significant $(p=0.137344)$. 
Fig. 5 Expression of Fox TFs in NIH3T3 cells. A) Amplification of Fox transcripts by first (a) and secondary/nested RT-PCR (b). Whereas in the first RT-PCR reaction no amplification products could be identified, the nested PCR performed on the first RT-PCR products as templates revealed products of the expected length of 449bp (Foxo3a), 631bp (Foxo1), 525bp (Foxa1), and 674bp (Foxj). Correct amplification products were verified by sequencing. B) Immunological detection of endogenous FOXA1 in NIH3T3 nuclei (a, red), nuclear stain with DAPI (b, blue), and merge image (c). Bars are of $5 \mu \mathrm{m}$.

Fig. 6 Knockdown of FOXA1::GFP by Foxa1 siRNA duplexes. A) Western blots demonstrating the reduction in FOXA1::GFP by Foxa1 siRNA. Foxa1::gfp was co-transfected with either control siRNA (control) or one of the Foxa1 siRNA duplexes A, B, or C (Foxa1 siA, B, or C). 48 hrs post-transfection cells were harvested, and the cell lysates were analysed by Western blotting. Detection of FOXA1 (green) and Tubulin (red) on the same blot. B) Efficient reduction of FOXA1::GFP by Foxa1 siRNA-mediated knockdown. The quantity of FOXA1::GFP was related to the quantity of $\alpha$-Tubulin in the same lane and the fold changes in the relative quantities calculated to the average of the relative quantity in control siRNA transfected cells. Three biological replicates for each RNA duplex. Student's T-test two-tailed, homoscedastic: siRNA A $p=0.412464$, siRNA B $p=0.004772^{* *}$, siRNA C $p=0.002733^{* *}$.

Fig. 7 Decreased expression of Foxa1, Odf2/ODF2 and CP110 by siRNA-mediated Foxa1 knockdown. A) Knockdown of Foxa1 and Odf2 transcripts by Foxa1 siRNA. NIH3T3 cells were transfected with either the scrambled control siRNA (control siRNA) or the Foxa1 siRNA (Foxa1 siRNA) and transcription of Foxa1 and Odf2 quantified by RT-PCR. The relative expression of Foxa1 or Odf2 was calculated to both housekeeping genes, Gapdh and Hprt, by $\Delta \mathrm{Ct}$. Significant reduced expression of Foxa1 $\left(p=0.00413455^{* *}\right)$ and Odf2 $\left(p=0.0000020216^{++++}\right)$related to the control siRNA. Three biological replicates always measured in triplicates. Student's T-test twotailed, homoscedastic. B) Western blot showing expression of ODF2 in NIH3T3 cells transfected with either the scrambled control siRNA (control siRNA, biological replicates \#1 to $\# 3)$ or the Foxa1 siRNA C (biological replicates \#1 to \#6). Cells were harvested 48 hrs posttransfection and cultivation in serum-deprived medium. Detection of ODF2 ( $100 \mathrm{kDa}$ ) and ßActin ( $42 \mathrm{kDa})$ simultaneously on the same blot using the fluorescent-labeled secondary 
antibody anti-rabbit IgGCW800. An unspecific band was observed $>100$ kDa. C) Foxa1 siRNA caused a reduction in ODF2 protein. The relative quantity of ODF2 was obtained by calculating the ratio between the quantity of ODF2 and ß-Actin in each lane, and relating the relative quantities to the average of the relative quantity obtained in control siRNA-transfected cells. Significant reduction of ODF2 expression by Foxa1 siRNA C $(p=0.000631 * * *)$. Six biological replicates each and a total of $n$ loadings: control $n=7$, siRNA B $n=7$, siRNA $C n=9$. D) Western blot showing expression of CP110 in control siRNA, and Foxa1 siRNA C transfected cells. (control siRNA: 4 biological replicates, Foxa1 siRNA: 5 biological replicates). CP110 (<130 kDa) and B-Actin ( $40 \mathrm{kDa}$ ) were both detected simultaneously on the same blot (in green). E) FOXA1 knockdown caused a decreased quantity of CP110 ( $\left.p=0.002232^{* *}\right)$. The relative quantity of CP110 was calculated as described for ODF2 quantification using the quantity of B-Actin as internal standard. For quantification six biological replicates for both, the control and siRNA, were used and a total of $n$ loadings quantified: control $n=7$, siRNA $n=8$. Always Student's T-test two-tailed, homoscedastic.

Fig. 8 FOXA1 is mandatory for primary cilia formation. NIH3T3 cells were transfected either with the scrambled negative control siRNA, or one of either Foxa1 siRNA duplexes A, B, or C. 24 hrs post-transfection the medium was exchanged for serum starvation medium for cilia induction. Cells were fixed either after $24 \mathrm{hrs}$ or $48 \mathrm{hrs}$ in serum starvation medium and ARL13B decorated immunologically. ARL13B-positive primary cilia were manually counted. All experiments were performed in triplicates and $\mathrm{n}$ cells were counted: Foxa1 siRNA A (24 hrs) $\mathrm{n}=1,599$, FoxA1 siRNA B (24 hrs) n=1,544, FoxA1 siRNA C ( $24 \mathrm{hrs}$ ) n=1,564, control ( $24 \mathrm{hrs}$ ) $\mathrm{n}=1,593$, FoxA1 siRNA A (48 hrs) $\mathrm{n}=1,593$, FoxA1 siRNA B (48 hrs) $\mathrm{n}=1,540$, FoxA1 siRNA C (48 hrs) $n=1,590$, control (48 hrs) $n=1,583$. Student's T-test two-tailed, homoscedastic, to control $24 \mathrm{hrs}\left({ }^{+}\right.$, siRNA A p =0.004569, siRNA B p=0.011402, siRNA C p=0.010086), or to control $48 \mathrm{hrs}$ $(*$, siRNA A $p=0.031788$, siRNA B $p=0.008451$, siRNA C $p=0.004429) . p<0.05^{*}, p<0.01 * *$, $\mathrm{p}<0.001^{+++}$.

Fig. 9 Interaction between FOXA1 and cJUN. A, B) Co-immune precipitation of FOXA::GFP did not reveal direct interaction with cJUN. Cells were transfected with expression plasmids encoding Foxa1::gfp, and Mekk1 (A) or Foxa1::gfp solely (B), and FOXA1::GFP captured by 
immobilized anti-GFP antibodies. Bead-bound proteins were eluted by boiling in SDS-sample buffer and the eluate, and aliquots of the input, the insoluble pellet, and the wash solutions were separated on denaturing SDS-gels. FOXA1::GFP was detected with anti-GFP antibodies (in red) and cJUN with anti-cJUN antibodies (in green). The unphosphorylated cJUN of $\sim 39 \mathrm{kDa}$ is present in $A$ and $B$, whereas the phosphorylated cJUN of $\sim 43 \mathrm{kDa}$ was detected only when Mekk1 was co-transfected (in A). Although the endogenous cJUN was detectable in the input fractions it did not co-precipitate with FOXA1::GFP (eluate). C) Co-localization of FOXA1::GFP and cJUN in transfected NIH3T3 cells. Antibody specificity of anti-FOXA1 antibody was proven by expression of FOXA1::GFP ( $a$, in green) and anti-FOXA1 antibody decoration ( $b$, in red). Cotransfection of cJun with Foxa1::gfp followed by anti-cJUN antibody decoration ( $\mathrm{f}$, in red) demonstrated overlapping FOXA1::GFP fluorescence (e, in green) with anti-cJUN decoration (h, merged image). Nuclear staining (c, g, in blue) and merged images ( $d, h$ ). Scales bares of 5 $\mu \mathrm{m}$. 
Fig. 1

A
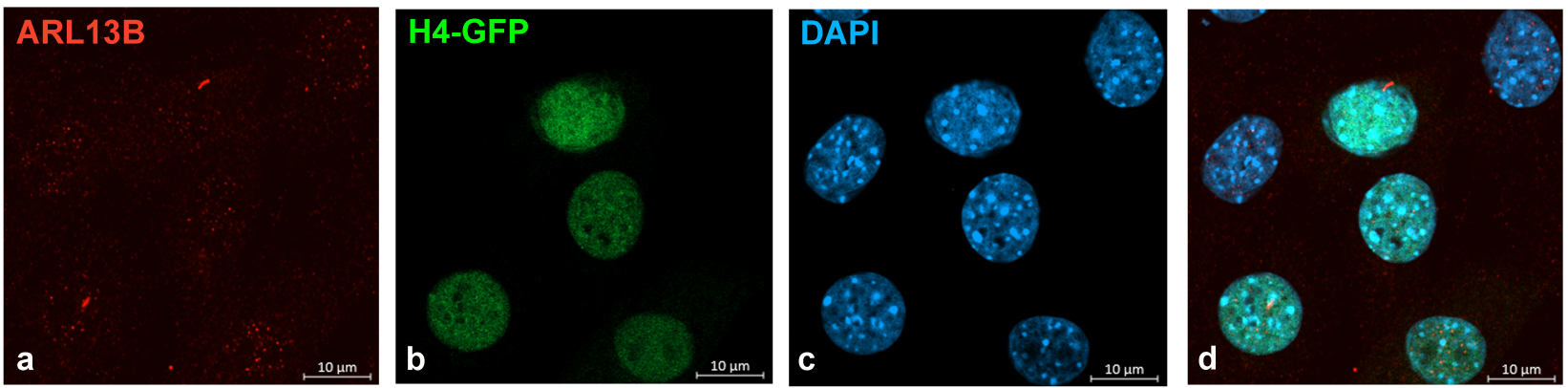

B

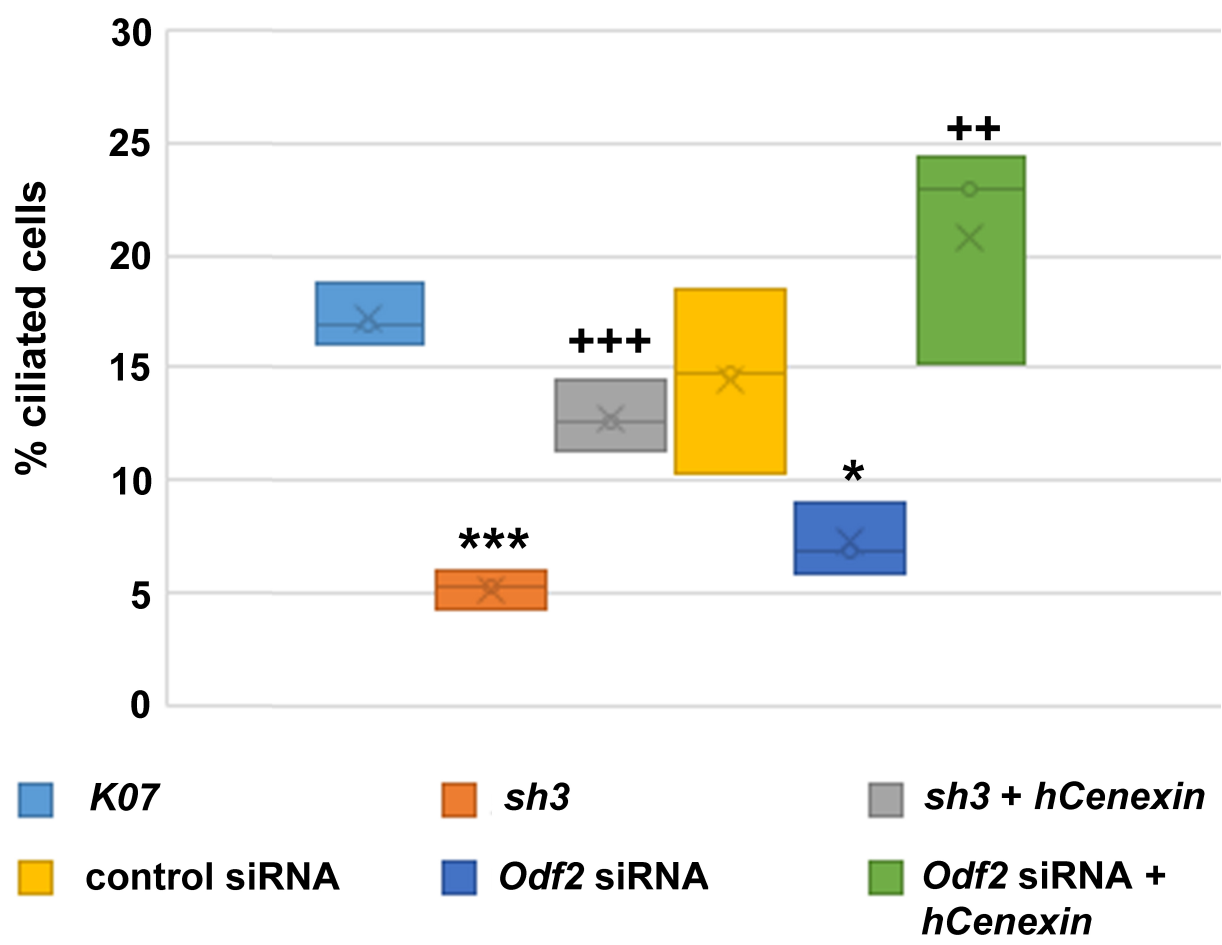


Fig. 2

A

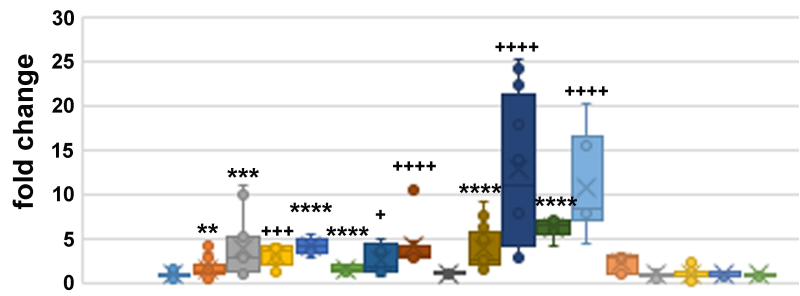

2.2-pGL3

+ C/ebp alpha

+ Mekk1 + C/ebp alpha

+ Mekk1 + Foxa1

+ cJun

+ Mekk1 + cJun + Foxa1

+ Mekk1 + cJun + C/ebp alpha + Foxa1

$\square+$ Foxo3a

+ Foxj
+ Foxa1

$\square+$ Foxa1 + C/ebp alpha

$\square+$ Mekk1

$\square+F o x a 1+c J u n$

$\square+M e k k 1+c J u n$

+ Mekk1 + cJun + C/ebpalpha

$+c J u n+C / e b p$ alpha + Foxa1

$\square+$ Foxo1

$\square+R f x 3+F o x j$

B

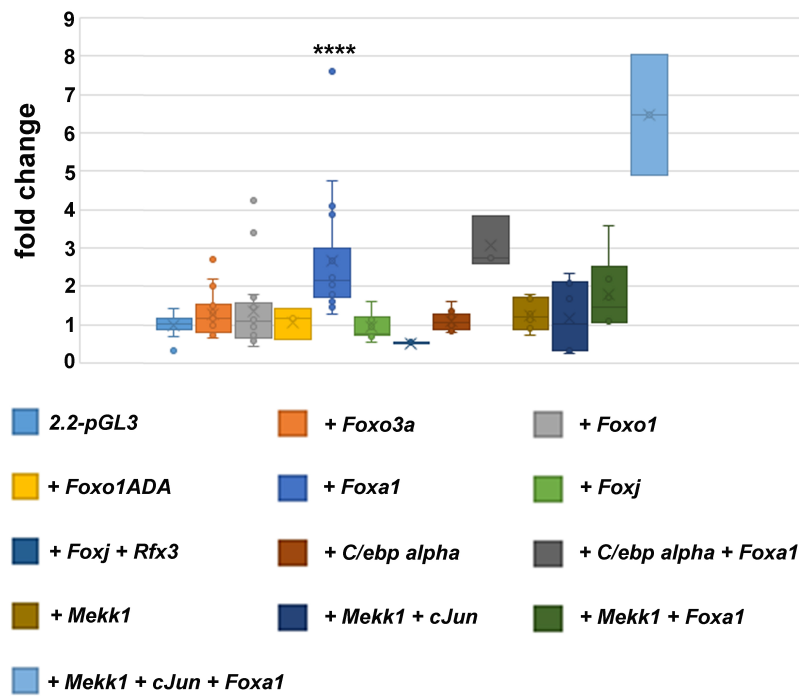


Fig. 3

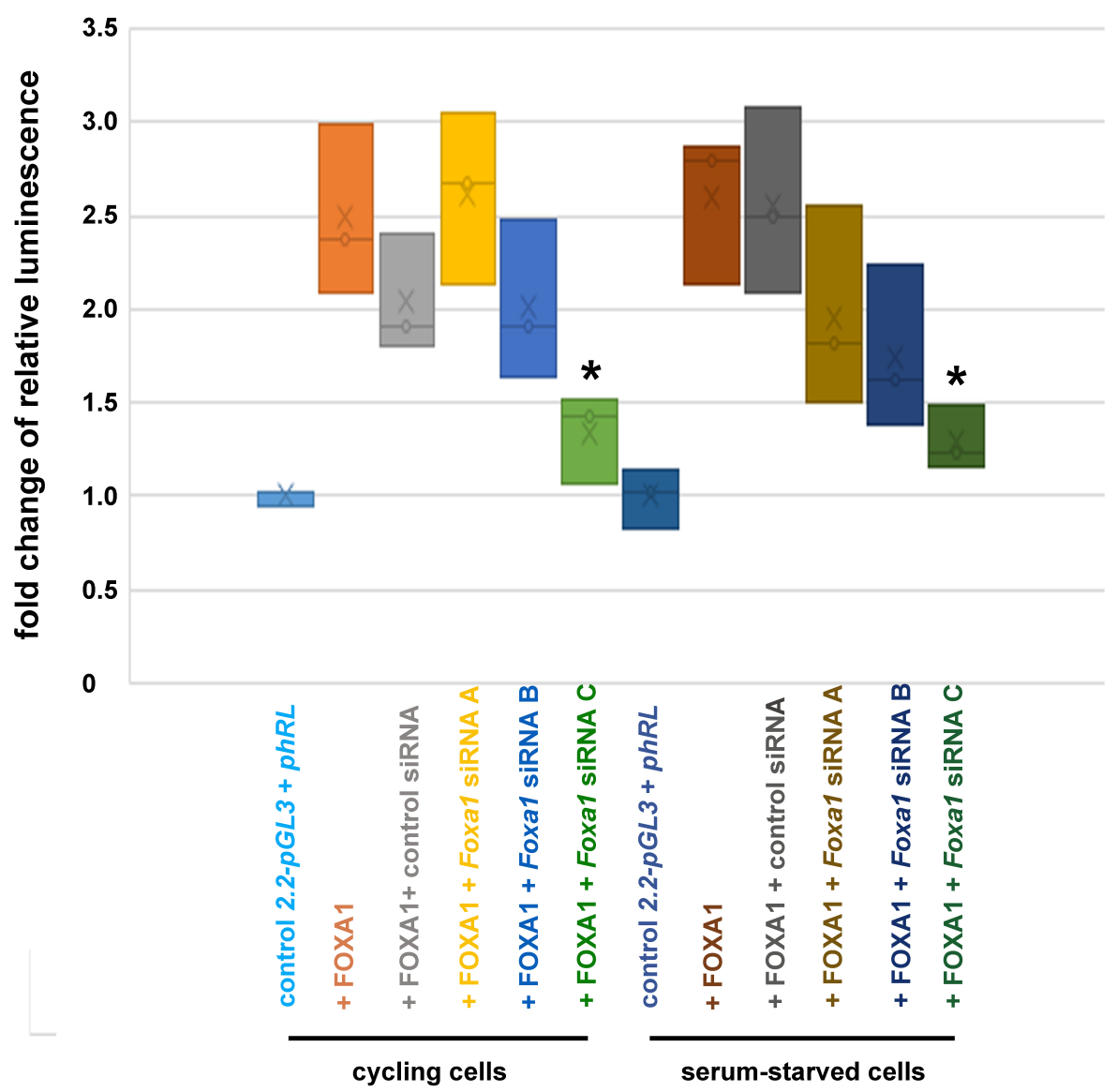


Fig. 4

A

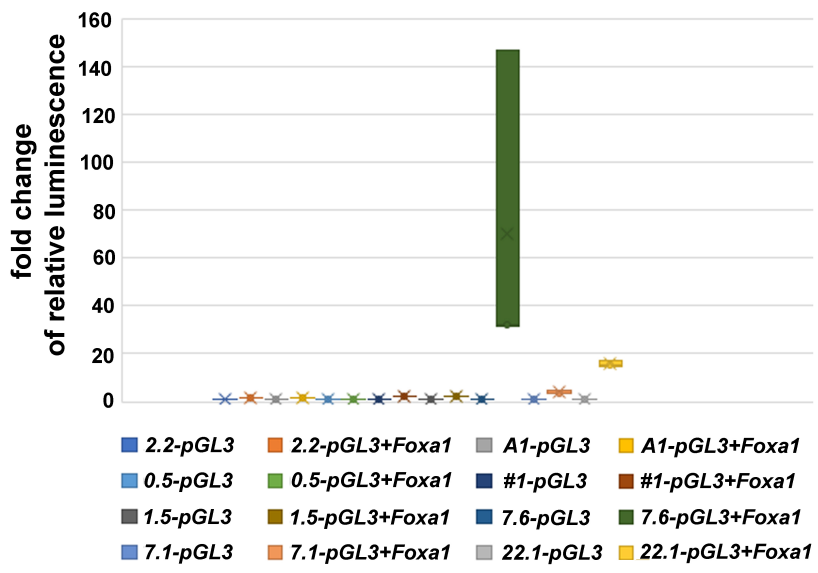

B

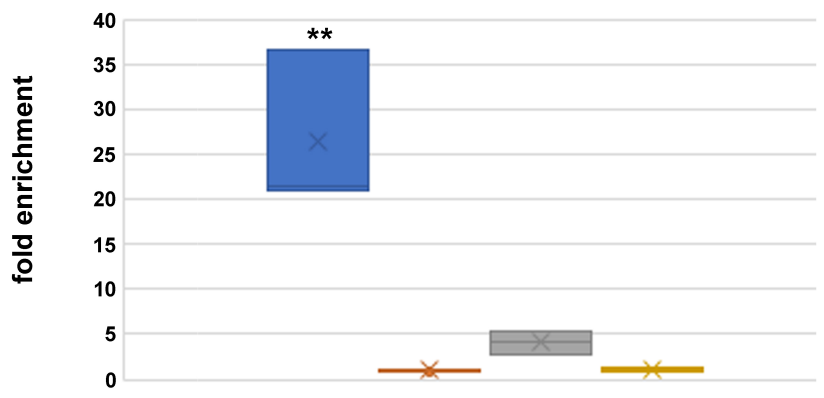

Foxa1+2.2+pGL3/anti-FOXA1 $\square$ Foxa1+2.2-pGL3/control lgG
2.2-pGL3/anti-FOXA1
$\square$ 2.2-pGL3/control IgG 
Fig. 5

A

$$
\frac{\text { Foxo3a }}{a} \frac{\text { Foxo1 }}{\text { b }} \frac{\text { FoxA1 }}{\text { a }} \frac{\text { Foxj }}{\text { b }}
$$

$1 \mathrm{kbp}-$

500 bp -

B

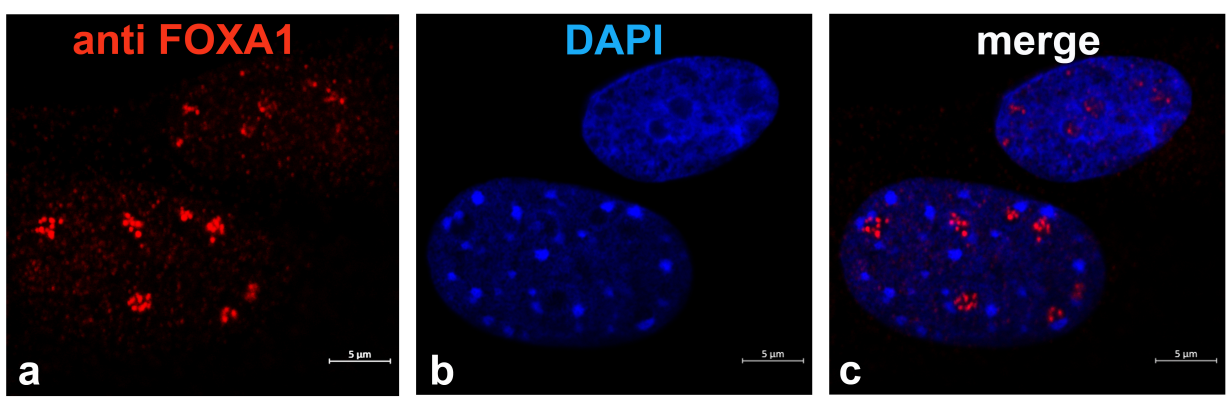


Fig. 6
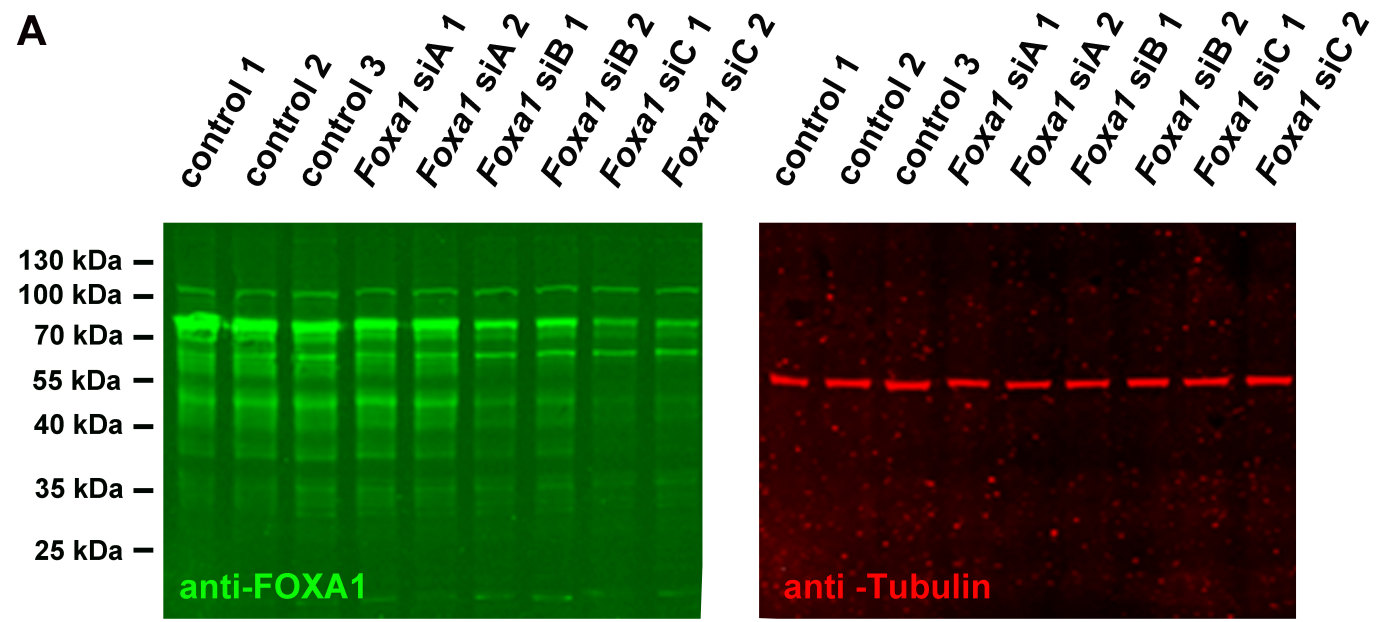

B

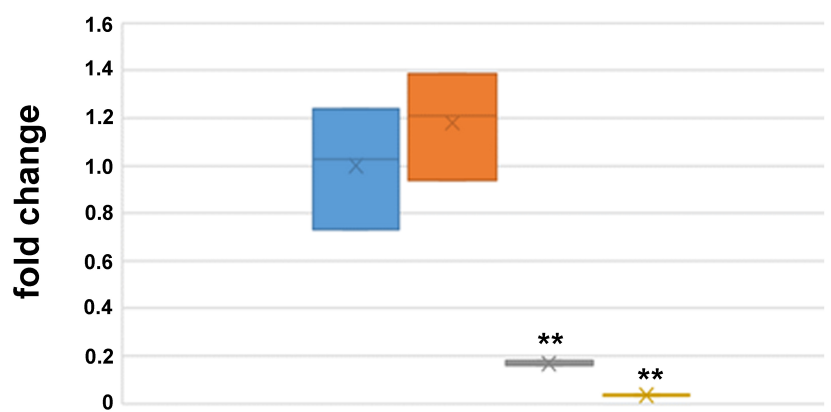

$\square$ control siRNA $\square$ Foxa1 siRNA A $\square$ Foxa1 siRNA B $\square$ Foxa1 siRNA C 
Fig. 7

A

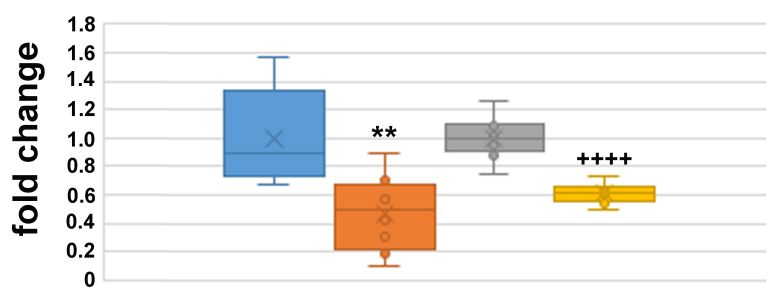

$\square$ Foxa1 expression, control siRNA $\square$ Foxa1 expression, Foxa1 siRNA

$\square$ Odf2 expression, control siRNA $\square$ Odf2 expression, Foxa1 siRNA

B

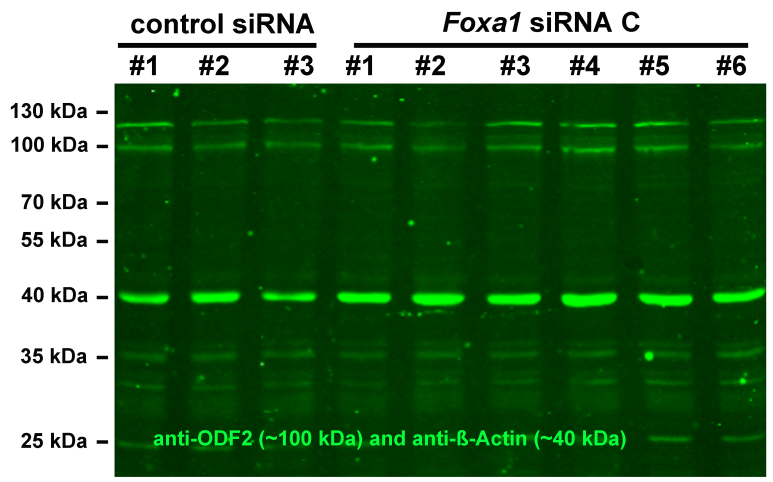

D

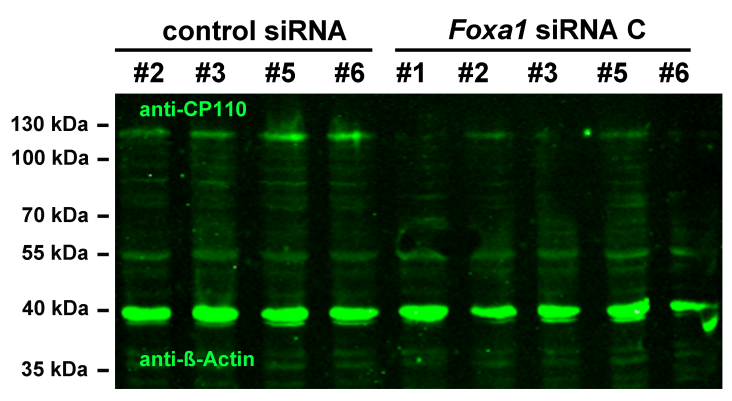

C

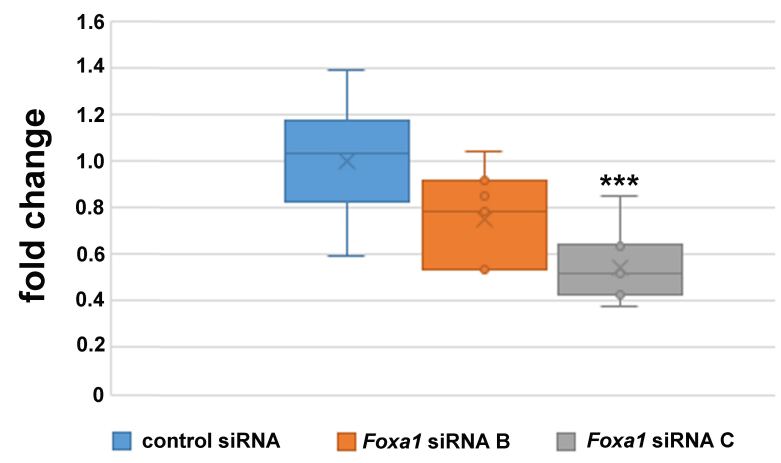

E

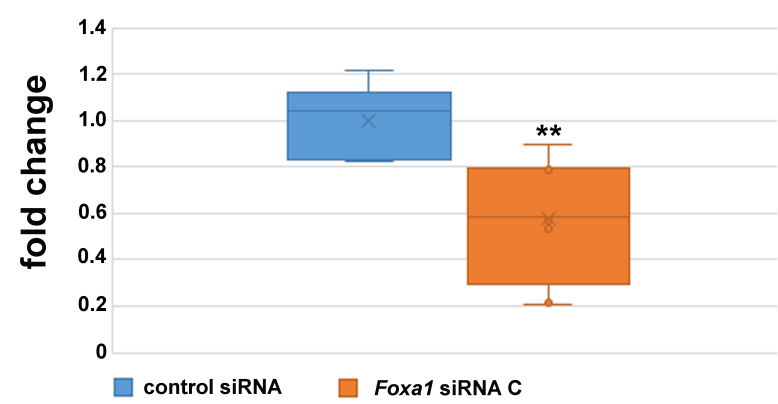


Fig. 8

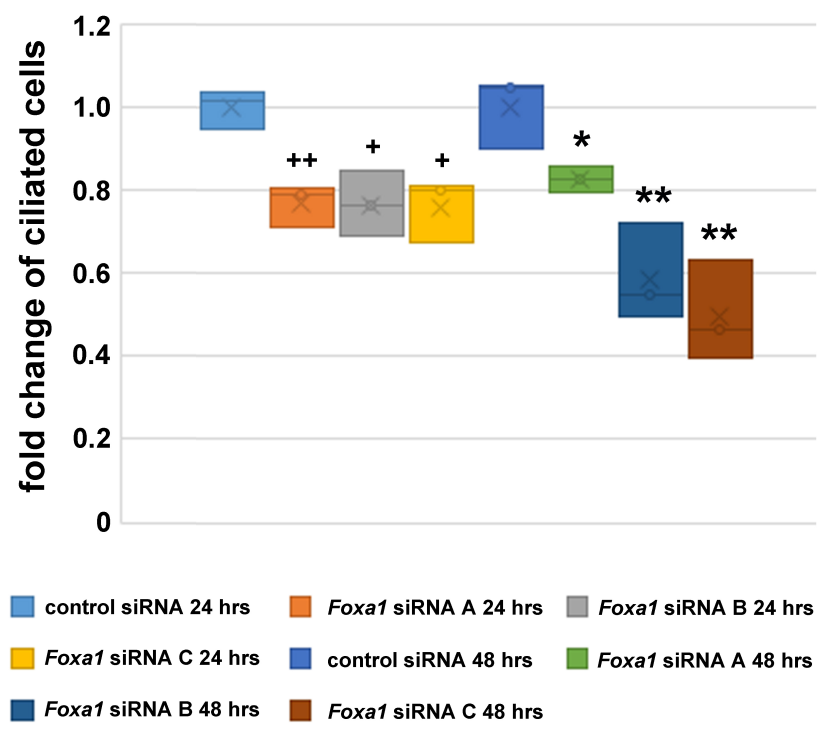


Fig. 9
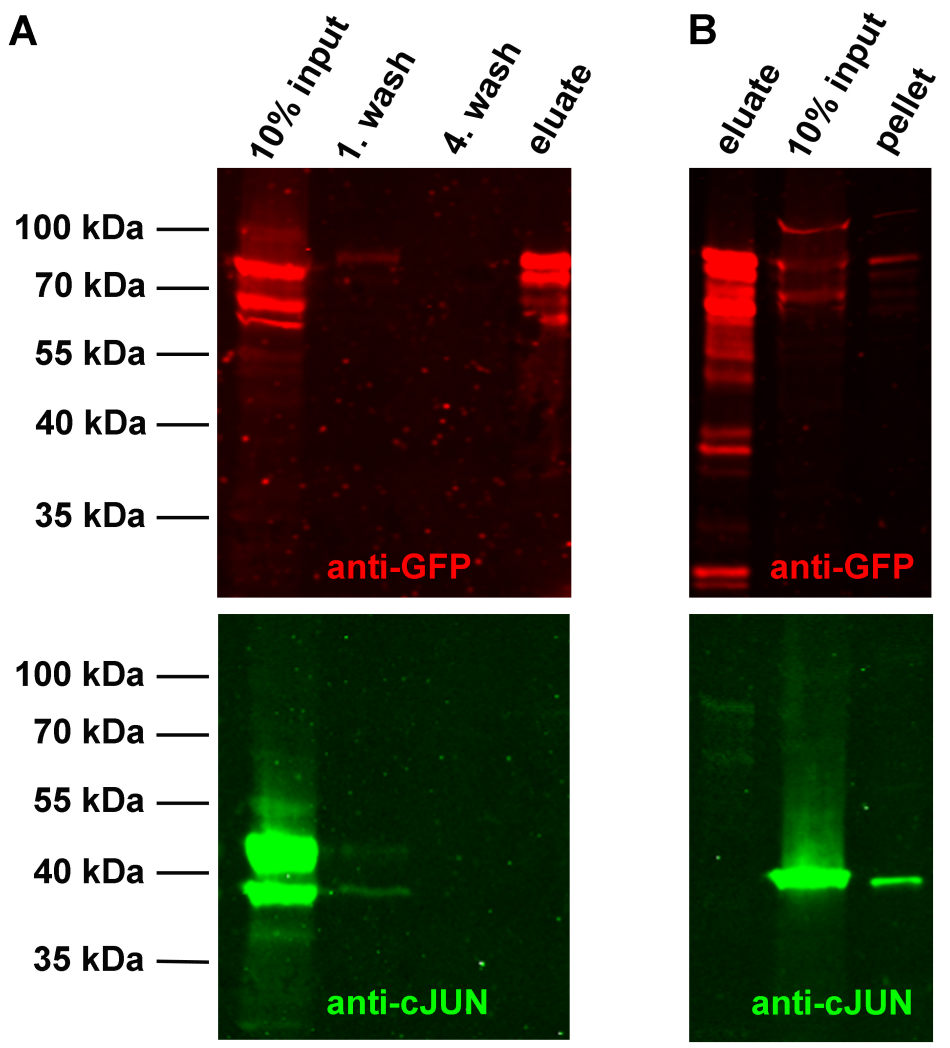

C
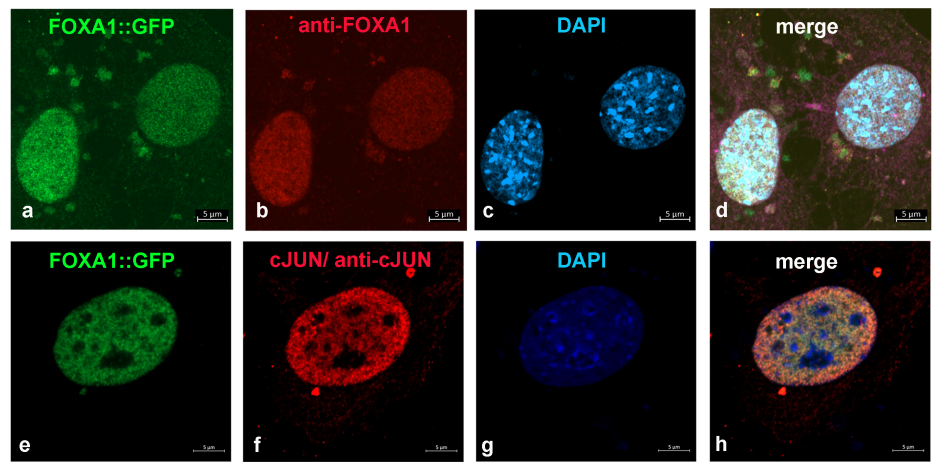
Czerny et al.,

FOXA1 is a transcriptional activator of Odf2/Cenexin

and regulates primary ciliation

Cellular and Molecular Life Sciences

Fig. $\mathbf{S 1}$

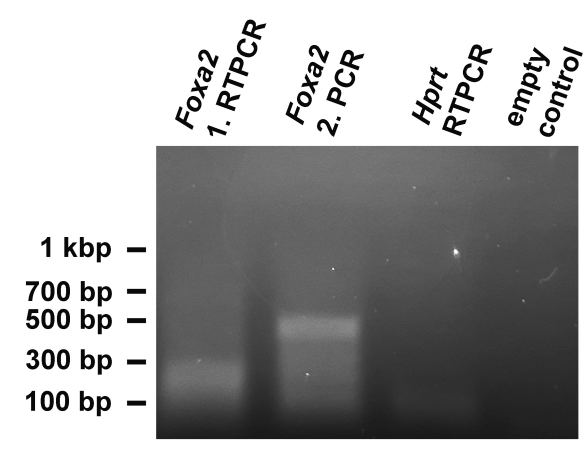

Expression of Foxa2 in NIH3T3 fibroblasts. Amplification of Foxa2 by RT-PCR on NIH3T3 cDNA using primer pair Foxa2for2 (AGCCGGGACACTAACAGTTC)/ Foxa2rev2 (GTTTGGCGTGTGTGTAGCTG) (Foxa2 1.RTPCR). The expected product of $541 \mathrm{bp}$ was not detected. Second PCR using $1 \mu$ of the first RTPCR reaction mix as template and primer pair Foxa2for1 (GTTGGCGGTCCCTTCCTTAT)/Foxa2rev1 (AGTTCATGTTGGCGTAGGGG) rvealed a product of the expected length of $429 \mathrm{bp}$. Amplification of Hprt on NIH3T3 cDNA with primer pair Hprtfor 2 (GGAGTCCTGTTGATGTTGCC)/ Hprtrev2 (GGGACGCAGCAACTGACATT) revealed a fragment of the expected size of $134 \mathrm{bp}$. No products were found when omitting the template in Foxa2 amplification (empty control). 